San Jose State University

SJSU ScholarWorks

Master's Theses

Master's Theses and Graduate Research

1992

\title{
The performance of individuals with severe physical disabilities on computer interface devices
}

Cynthia Lau

San Jose State University

Follow this and additional works at: https://scholarworks.sjsu.edu/etd_theses

\section{Recommended Citation}

Lau, Cynthia, "The performance of individuals with severe physical disabilities on computer interface devices" (1992). Master's Theses. 284.

DOI: https://doi.org/10.31979/etd.rc8m-pdcw

https://scholarworks.sjsu.edu/etd_theses/284

This Thesis is brought to you for free and open access by the Master's Theses and Graduate Research at SJSU ScholarWorks. It has been accepted for inclusion in Master's Theses by an authorized administrator of SJSU ScholarWorks. For more information, please contact scholarworks@sjsu.edu. 


\section{INFORMATION TO USERS}

This manuscript has been reproduced from the microfilm master. UMI films the text directly from the original or copy submitted. Thus, some thesis and dissertation copies are in typewriter face, while others may be from any type of computer printer.

The quality of this reproduction is dependent upon the quality of the copy submitted. Broken or indistinct print, colored or poor quality illustrations and photographs, print bleedthrough, substandard margins, and improper alignment can adversely affect reproduction.

In the unlikely event that the author did not send UMI a complete manuscript and th re are nissing pages, these will be noted. Also, if unauthorized copyright material had to be removed, a note will indicate the deletion.

Orgr ize materials (e.g., maps, drawings, charts) are reproduced by sectioning the original, beginning at the upper left-hand corner and continuing from left to right in equal sections with small overlaps. Each original is also photographed in one exposure and is included in reduced form at the back of the book.

Photographs included in the original manuscript have been reproduced xerographically in this copy. Higher quality $6^{\prime \prime} \times 9^{\prime \prime}$ black and white photographic prints are available for any photographs or illustrations appearing in this copy for an additional charge. Contact UMI directly to order.

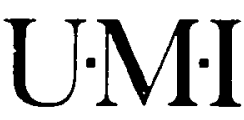

University Microfıms Internatıonal

A Bell \& Howell Information Company

300 North Zeeb Road. Ann Arbor. M! 48106-1346 USA

$313 / 761.4700 \quad 800: 521.0600$ 

Order Number 1948210

The performance of individuals with severe physical disabilities on computer interface devices

\author{
Lau, Cynthia, M.S. \\ San Jose State University, 1992
}





\title{
THE PERFORMANCE OF INDIVIDUALS WITH \\ SEVERE PHYSICAL DISABILITIES \\ ON COMPUTER INTERFACE DEVICES
}

\begin{abstract}
A Thesis
Presented to

The Faculty of the Department of occupational Therapy San Jose State University
\end{abstract}

In partial Fulfillment

of the Requirements for the Degree

Master of Science

By

Cynthia Lau, OTR

May, 1992 
APPROVED FOR THE DEPARTMENT OF OCCUPATIONAL THERAPY

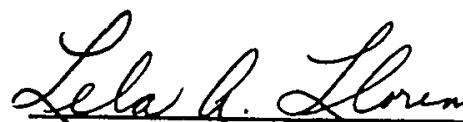

Lela A. Llorens, Ph.D., OTR, FAOTA

Sorraixe Pedreti.

Lorraine Pedretti, M.S., OTR

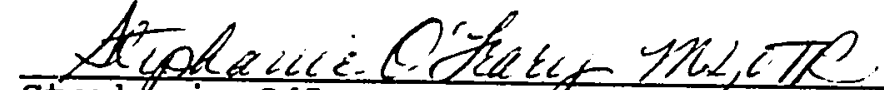

Stephanie O'Leary, M.S., OTR

APPROVED FOR THE USIVERSITY

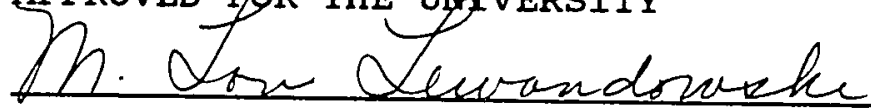




\section{ABSTRACT}

THE PERFORMANCE OF INDIVIDUALS WITH SEVERE PHYSICAL DISABILITIES ON COMPUTER INTERFACE DEVICES

by

Cynthia Lau

This study employed a descriptive case study

desir to examine and compare subjects' performance using three computer input devices: Tongue Touch Keypad, HeadMaster, and a mouthstick. The sample consisted of four students with severe physical disabilities, between the ages of 17 and 21, and enrolled in an Adaptive Computer Application Class at Foothill College. Components of performance examined included: input speed, accuracy, and level of perceived exertion. The study also investigated subjects' personal acceptability level toward each of the interface devices. Results revealed that accuracy of input did not vary significantly but there was a substantial difference of level of perceived exertion and input speed between the three interface devices. Results also suggest that overall performance did not necessarily affect personal acceptability ratings of the device. Information from this study will help occupational therapists better evaluate the effectiveness and desirability of assistive computer devices for persons with severe physical aisabilities. 


\section{ACKNOWLEDGEMENTS}

I would like to express my appreciation and gratitude to Lela Llorens, Ph.D., OTR, FAOTA, Stephanie O'Leary, M.S., OTR, and Lorraine Pedretti, M.S., OTR who with their expertise in the fieid of occupational therapy assisted in the completion of this thesis.

I would also like to thank the subjects, subjects' families, staff at Foothill college, and Zofcom Incorporated for their interest and cooperation in making this research study a success.

And last, but certainly not least, I could not have accomplished this study without the constant support and assistance of my friends: Willard Hong, Kan Wong, and Kenneth $\mathrm{Ng}$.

Thank You. 


\section{TABIE OF CONTENTS}

\section{Chapter 1}

Page

INTRODUCTION

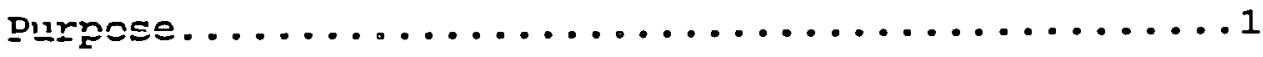

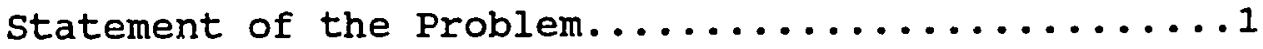

objectives..........................4

Questions............................

Definitions.......................

Assumptions.........................

Limitations.........................

Significance of the study................

\section{Chapter 2}

LITERATURE REVIEW

Introduction. ......................... 12

Occupational Therapy for the Person with Severe

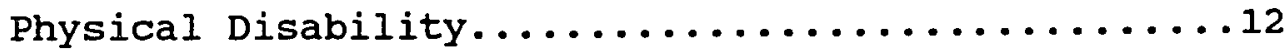

Persons with Severe Physical Disability and

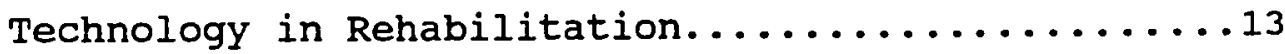

Occupational Therapy Frame of Reference......... 19

summary ...............................

Chapter 3

DESIGN AND METHODOLOGY

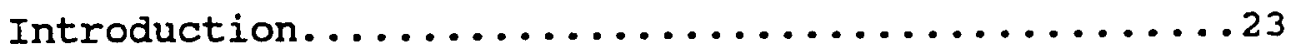

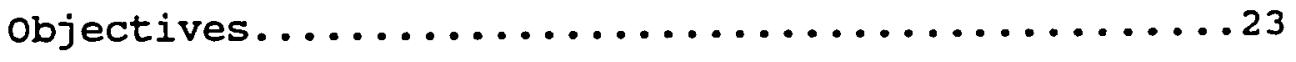

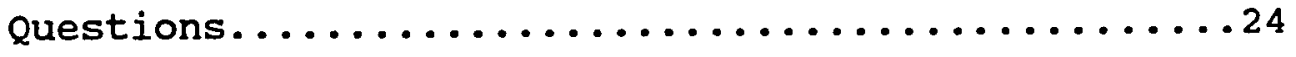




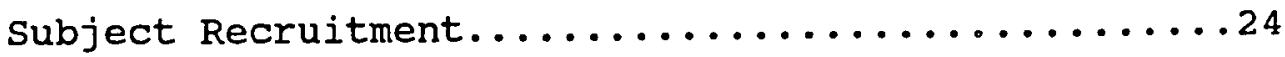

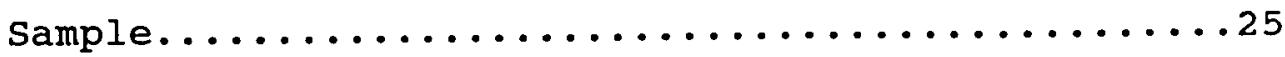

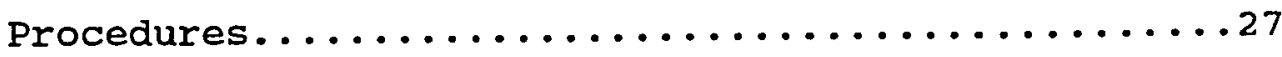

Quantitative and Descriptive Technique..........29

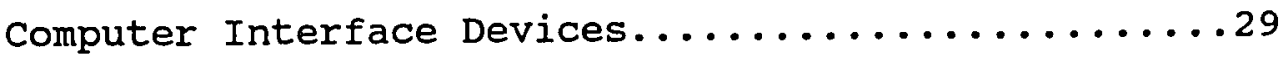

Chapter 4

ANALYSIS OF DATA

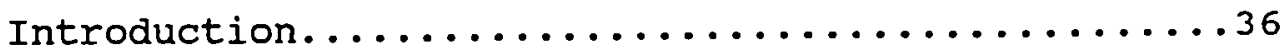

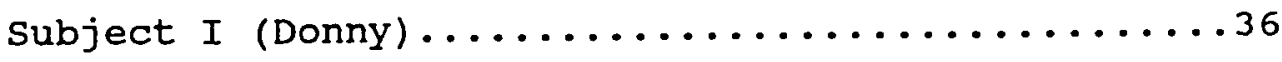

Subject II (Ernie)....................45

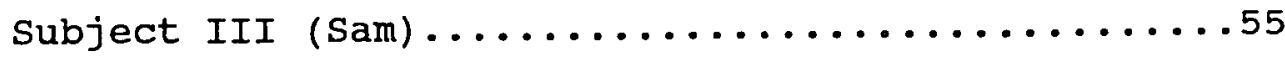

Subject IV (Michael)....................64

Chapter 5

SUMMARY AND IMPLICATIONS

Introduction. .........................

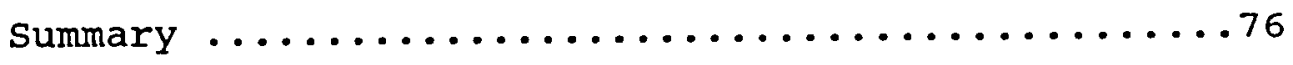

observations........................82

Implications....................... 83

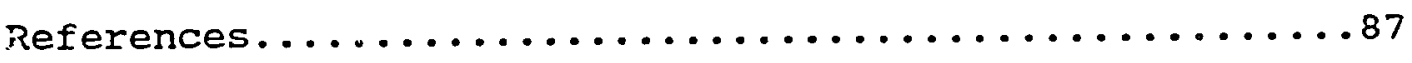

Appendix A...............................

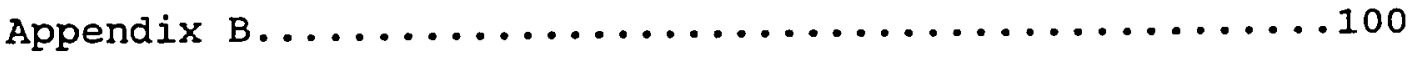

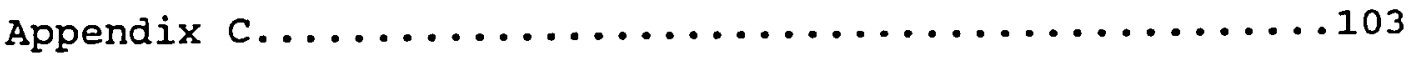

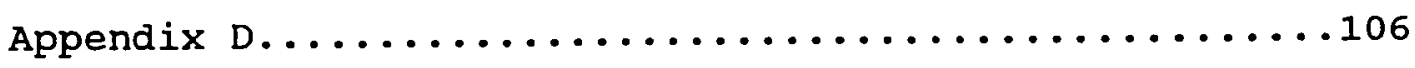

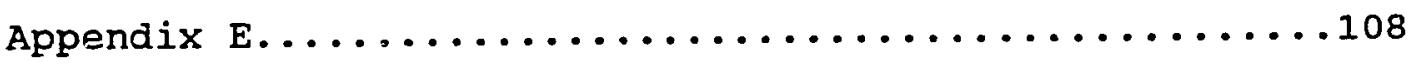

$v i$ 
Appendix F...................................

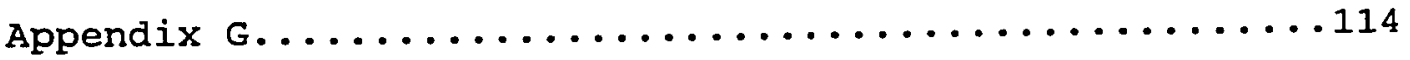

Appendix 


\section{List of Figures}

Figure

page

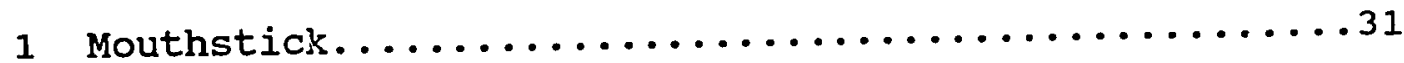

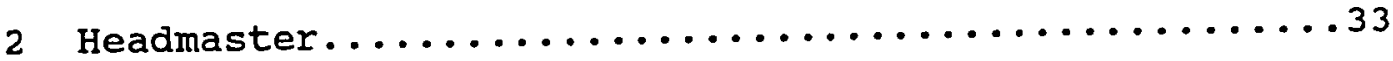

3 Tongue Touch Keypad............................. 35

subject 1 (Donny)

4 Three Minute Typing Tests...................40

5 Fatigue Ratings.......................42

6 Personal Acceptability....................43

Subject 2 (Ernie)

7 Three Minute Typing Tests....................... 49

8 Fatigue Ratings........................ 51

9 Personal Acceptability ................... 53 Subject 3 (Sam)

10 Three Minute Typing Tests................... 59

11 Fatigue Ratings........................60

12 Personal Acceptability....................62 Subject 4 (Michael)

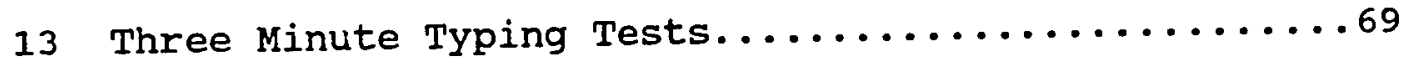

14 Fatigue Ratings........................

15 Personal Acceptability.................... 72 
CHAPTER 1

\section{INTRODUCTION}

Purpose

The purpose of this study was to determine 1) input speed, accuracy, and level of perceived exertion by persons with severe physical disabilities on three head operated systems used as computer interface devices, and 2) the attitude of subjects toward each of the interface devices in terms of the level of personal acceptability.

\section{statement of Problem}

Thousands of individuals in the United States have severe physical disabilities as a result of congenital conditions, accidents, or disease. Spinal cord injury, cerebral palsy, and muscular dyscrophy are a few conditions that may result in severe involvement of all four extremities.

Approximately 200,000 individuals with some degree of impairment from spinal cord injury resulting from trauma, Aisease, or congenital anomalies presently live in the United States (Schneider in Umphred, 1985). A conservative estimate of the prevalence of cerebral palsy is about 900,000 cases in the United States. This number is continuing to increase as more severely involved children with cerebral palsy are surviving and living longer (Easton 
\& Halpern in Stolov \& Clowers, 1981). Muscular dystrophy, which may leave an individual severely disabled by the middle teens, occurs in 4 cases per 100,000 population (Corcoran in Stolov \& Clowers, 1981). With any one of these conditions, a person may be limited in movement from the legs to the head depending on the level of severity. With limited movement, a person has increasing difficulty accomplishing roles in the areas of work, selfcare, and play. These roles include those of employee, family member, or student. Persons with spinal cord injuries have a higher rate of unemployment and much more daily free time than their nondisabled peers (Yerxa \& Locker, 1990) - A physical disability may deter competence and achievement behaviors necessary for a person's social role. With a decrease in role achievement, there can be a detrimental effect on the quality of life for these individuals. According to the occupational behavior frame of reference, it is the purpose of occupational therapy to prevent and reduce incapacities resulting from illness and to activate residual adaptation forces within a patient (Reilly, 1969). Approximately 40 percent of occupational therapists use computers for treatment of their patients (American Occupational Therapy Association, 1990). Occupational therapists along with other professionals are involved with selecting and training clients to access computers 
through special input devices and considered to be well qualified to take positions within the expanding field of adapted computer technology (Gross \& Burnett, 1989). There is a need, however, for occupational therapists to know the expected learning curve, speed, and the comfort level of a particular interface device for a client before recommending an investment of a large sum of money to buy the device. Adaptive devices can be very expensive, ranging up to thousands of dollars. Before buying or even training on such an expensive piece of equipment, it would be prudent to know how efficient or fast the disabled person will be able to learn to use it. It would also be worthwhile to know how a disabled person feels about using the device. In addition, normative data on input speed are needed to provide clinicians with a basis for comparison when training patients on head operated systems as are data on the level of perceived exertion experienced by the subjects for each device. 


\section{Objectives}

The objectives for this research were:

1. To explore the input speed and accuracy in performance by persons with severe physical disability for three computer interface devices.

2. To examine the attitude of persons with severe physical disability toward specialized computer interface devices and 3. To generate data that will be used to aid in selection and evaluation of adaptive computer devices.

\section{Research Questions}

The research questions to be answered in this study were:

1. What are the input speed, accuracy, and rate of perceived physical exertion of persons with severe physical disabilities on each of the following computer interface devices?

a. Adlib Mouthstick with bend

b. Head Master sip and puff system

c. Zofcom Tongue Touch Keypad

2. What is the attitude of persons with severe physical disability toward the acceptability of each of the three interface devices under training conditions? 


\section{DEFINITIONS}

Acceptability - the extent to which the subject is psychologically comfortable with using the device in public or private as measured on a rating scale.

Accuracy - percentage of characters entered correctly into the computer.

Adlib Mouthstick - a wand held in place by the person's sustained bite which can be used as a page turner or typing stick. For the purpose of this study, it is considered to be a computer interface device.

Computer interface devices - input equipment used to access the computer.

HeadMaster- is a mouse emulation adaptive device. It consists of a headset with three ultrasonic senders and a receiving unit. The receiving unit rests on the top of the computer monitor. As the person moves his or her head, the cursor moves on the screen. selection occurs through a sip and puff activated switch on the headset. The user puffs in the straw like switch when the cursor rests on the desired character or icon. Input speed - number of characters per minute entered into the computer.

Performance - the quality and degree of speed, accuracy, and level of perceived exertion evident while using each of the interface devices. 
Persons with severe physical disabilities - a person who has limited use of all four extremities as a result of injury, congenital condition, or disease.

Rate of perceived exertion - individual's perception of exertion during physical work as measured by the Borg's scale. (Borg, 1982).

Tongue Touch Keypad - manufactured by Zofcom, Incorporated is a computer interface device consisting of a intraoral retainer-like tongue switch operated by tongue elevation movements and an infrared receiver. The receiver unit is placed next to the computer. As the user elevates his tongue to press different keys on the keypad, the cursor moves in corresponding directions on the screen. Selection occurs through activation of the middle key when the cursor rests on the desired character or icon.

\section{A88UMPTION8}

In this study, it was assumed that:

1. Persons with severe disabilities wish to master the necessary skills required to control their environment through adaptive computer technology.

2. The components of usage (speed, accuracy, and exertion) make up the level of performanse of the subject using the interface device. 
3. The questions on the Personal Acceptability

Questionnaire accurately measured personal acceptability. 4. The subjects' responses on the personal acceptability questionnaire, subject profile, and exit interview are honest and genuine.

\section{IIMITATIONS}

The limitations of the study were identified.

1. Due to time and resource limitations, the number of subjects was limited to five. It was difficult to produce statistically significant results with such a small sample size.

2. Due to the specific requirements of the subjects in the study, there was not a random sample of subjects. Therefore, one cannot generalize the findings.

3. Due to the very limited research in this area, the Personal Acceptability Questionnaire has not been subjected to validity or reliability testing.

4. Results may not be generalized to larger population of persons with disabilities because the subjects were an unique group of individuals eligible for entrance to the community college and manage their own transportation services. The individual who has transportation and the initiative to seek out the class may perform differently on devices then people without the inner and external resources. 
5. The specific age range of the subjects was 17 to 21 years old. People at this young age without any cervical limitation in range of motion, visual deficits, and reaction times difficulties will have different performance rates than older people with long standing physical disabilities.

\section{SIGNIFICANCE OF THE STUDY}

With the recent advancement in adaptive computer technology, persons with severe physical disabilities can have better access to environmental control, education, work, and leisure (Bryant, 1990; Dickey \& Shealey, 1987; Stride, 1985). It is important for the individual with a disability to have computer access in order to accomplish the same daily living activities as the nondisabled individual; such activities include written communication, environmental control, recreational pursuits, financial planning, and information retrieval (Vanderheiden, 1983). In one computer skills training program at a rehabilitation facility, severely disabled inpatients were observed to attain psychological benefits such as increased self-esteem, social interaction and expressed enthusiasm for newly acquired computer skills (Links \& Frydenberg, 1989). Occupational therapists with their clinical and educational backgrounds are well qualified to provide technological device evaluation and training to people with 
physical disabilities (Trefler, 1987; Vanderheiden, 1987). According to the occupational behavior frame of reference, one priority of occupational therapy is to activate residual skills to attain social role acquisition (Reed, 1984). The acquisition of word processing skills can enable disabled persons to complete educational and vocational goals which are congruent with fulfilling the role of student and employee (Sunahara, 1990).

There are many computer interface devices available to disabled individuals. Some of these can range from $\$ 30.00$ for a mouthstick to $\$ 12,000$ for a voice activated system. It is important for therapists to know how well these devices work for the intended population before recommending their patients to invest time and finances into the device.

A review of the literature has not revealed any comparison studies on the performance of computer interface devices. In addition, there has been limited investigation of the attitude of a person with severe disabilities toward "high technology" computer interface devices. Since personal acceptability is an important criterion of evaluation when using a computer input device that is different than the norm such as the standard keyboard or mouse, it is an important factor to study.

Frequently used computer interface devices at the Veteran's Administration Hospital in Palo Alto for high 
level quadriplegic patients are the standard mouthstick and the HeadMaster system. The mouthstick can be used in other activities such as turning pages, writing, and painting. It is also inexpensive compared to other interfaces. The HeadMaster system uses a respiration sip and puff method to interface with the computer. Both interfaces require a moderate amount of head movement to achieve input. Another interface device is the Zofcom Tongue Touch Keypad. This interface works by tongue movement alone and is another viable option for persons with physical limitations in all four extremities. Even though these interface devices may be used by individuals with severe physical disabilities, there exists no published research to describe performance. The significance of this study was threefold. First it investigated the performance of persons with severe physical disabilities on three interface devices that have been specifically designed for this population. Performance was measured by three components of usage: speed of text input, accuracy, and level of perceived exertion while using the device. These components of usage are not only relevant for word processing but for any data entry or environmental control input that the person with a physical disability may use throughout his day. This study also focused on the acceptability of the device for the person with a disability. It is important to know the person's attitude 
toward the device because it will affect how much they will use the interface in their daily life. Thirdly, data derived from this study on the subjects' performance and the acceptability of adaptive computer interface devices generated information that will assist therapists in determining which interface device illay be most appropriate for a client therefore optimizing the quality of intervention. 
CHAPTER 2

\section{LITERATURE REVIEW}

Introduction

Literature reviewed for this study focused on occupational therapy as treatment for the person with severe physically disabilities, studies related to life satisfaction and severe disabilities, technology available for the severely disabled, and the occupational behavior frame of reference.

\section{Occupational Therapy for the}

\section{Person with severe Physical Disability}

occupational therapy has traditionally been part of the rehabilitation for persons with severe disabilities. Since persons with severe disabilities are living longer lives because of the advances in medical technology, establishing realistic long term rehabilitation goals has become more vital (Howell, 1978). Long range goals of rehabilitation for the patient include (1) achieving the maximal level of self-care independence possible, (2) accepting the disability, (3) resuming meaningful family, social, community, vocational and leisure roles (Spencer, 1983). The purpose of occupational therapy is congruent with the goals of rehabilitation. For example, the general occupational therapy objectives for the person with spinal cord injury are to (1) increase strength of all innervated 
muscles, (2) maintain range of motion, (3) increase physical endurance, (4) train in the use of assistive devices, (5) develop maximal independence in activities of daily living, (6) explore vocational potential, and (7) aid psychological adjustment to the disability (Pedretti \& Adler, 1990). To achieve the above mentioned goals, occupational therapists use various tools in activities of daily living training. Some of these include splints, wheelchairs, assistive self-care devices, activity modification, and now computer systems (Spencer, 1983). Occupational therapists have traditionally provided technological device evaluations and training to the disabled population (Trefler, 1987). Occupational therapists have the clinical and educational background that provide an excellent basis for applying technology in rehabilitation (Vanderheiden, 1987). The occupational therapy department at Palo Alto Veteran's Administration Medical center and other Veteran's Administration Medical Centers have integrated full computer access evaluation into their rehabilitation program protocol (Bryant, 1989; O'Leary, Saxena, Linder,\& Perkash, 1990).

\section{Persons with Bevere Physical Disability and Technology in Rehabilitation}

Decker and Schulz (1985) indicated that persons with spinal cord injury who experienced high levels of life 
satisfaction reported high levels of perceived control and/or were employed to some capacity. Among those employed, there was a high level of job satisfaction. This study also indicated that "...occupational therapist's intervention in helping the injured person perceive control over the physical and psychological environment may be central to subsequent life satisfaction." (Decker \& Schulz, 1985). Computer access can be a valuable link in attaining optimal control of the environment for persons with severe physical disability.

The recent boom in computer technology can provide valuable tools for the rehabilitation and treatment process of disabled individuals. Burkhead, Sampson, and McMahon (1986) claim that providing disabled persons with access to computer technology is as important as providing architectural accessibility. Computer technology is pervasive in all aspects of daily life such as education, employment and banking. Without devices to access computer technology, disabled persons will be further excluded from society (Burkhead, Sampson, \& McMahon, 1986). The use of the computer can provide opportunities for communication, motor, cognitive and vocation skills training, control of the environment, and the acquisition of valued skills and status in society (Kanellos, 1985).

There are many computer interface devices on the market 
for disabled individuals. The diversity of input and output devices makes the computer readily accessible to persons with orthopedic dysfunction as a result of congenital, developmental, or traumatic causes (Spicer \& McMillan, 1987). Literature on the performance by persons with severe disabilities on computer interface devices is very limited. In 1989, one study used a single subject design with five disabled persons to obtain typing scores of 17 to 24 words per minute using the Long Range optical Headpointer with a wora prediction program (Smith et al., 1989). Bryant (1990), a patient with a c-4 spinal cord injury at a Veterans Administration Hospjtal in Virginia, described his personal experiences in evaluating various interfaces designed for people with severe mobility impairments. Computers are increasingly playing a vital role in rehabilitation and employment for the population of persons with disabilities (Bowe \& Iittle, 1984). Through access to a computer system, an occupational therapist can train a client to use an environmental control unit, perform word processing or data entry for vocational pursuits, utilize perceptual/cognition retraining programs, and use various programs for leisure (Spicer \& McMillan, 1987; Spencer, 1983) .

Dickey and Shealey (1987) have reported that occupational therapy can provide the missing link between 
persons with severe disabilities and the environment through the training and consultation on the use of environmental control systems. Environmental control systems can be used to permit severely disabled individuals to use daily living tools such as telephone, radio, television, bed controls, page turner, and video equipment. A person with no hand function can operate an environmental control unit by being able to input through a specialized interface device hooked to a computer or remote control module. A person immobilized in bed or in a wheelchair may have a more productive and interactive day being able to talk on the phone, read, watch television, listen to the radio, and readjust his or her position.

Horace Bryant, a C4 quadriplegic, 47 year old veteran is an evaluator of computer interface devices at Hunter Holmes McGuire VA Hospital in Richmond, Virginia. Among those he evaluated were: MacMouth Mouse, HeadMaster, and the FreeWheel Pointer system. He plans to begin a career in home desk top publishing using one of the specialized interface devices with the computer (Bryant, 1989). "For a high level quadriplegic, being able to access and use a personal computer efficiently is only the first step; the ultimate goal is vocational training that could lead to meaningful employment. Taking full advantage of the 
available technology and pursuing it to the fullest is a significant personal accomplishment" (Bryant, 1989, pp.7).

With equipment adaptation such as specialized interface devices, mouthsticks, and specialized software, jobs as programmers and terminal operators are accessible to persons with quadriplegia. Technology with an appropriate training program and identification of employment opportunities will reduce the physical demands of a job so that disabled persons can compete with nondisabled people (Stride, 1985). Besides the vocational aspect of high technology influence on the functional capacity of a disabled person, there is the avocational aspect. Leisure skills through computer games made possible by specialized interface devices should be of interest to rehabilitation workers (White, Wussow, \& Merritt, 1983). Ability to play a computer game may give the person with physical limitations a serise of mastery and competence and a means of interacting with friends, family members, and other computer users in a fun and competitive manner.

With the help of a specialized interface device, a person with a physical disability can have access to a computer system that offers the opportunity to fulfill self care, work and leisure roles. Vanderheiden (1987) has reported the importance of appropriate therapy and training with any selected rehabilitation technology. The client 
needs training rot only in how to operate the technological aid, but also in how to effectively use it to meet his or her needs. This adaptive technology along with the proper training will increase the quality of life of persons with severe disabilities by allowing them to participate in life roles and increasing the opportunity to becoming more independent individuals.

Depending upon the severity of any physical disability, computer interface devices can take a variety of forms. Some individuals have only head control such as persons with high level spinal cord injury, severe spastic quadriplegia, or advanced stage of muscular dystrophy. For these individuals, headpointing, eye control, chin control, mouth or tongue control, and voice activation are viable alternatives.

Angelo (1989), used a single subject design involving five subjects to compare three optical headpointing systems as computer input devices. The hypothesis of the study was that no difference existed in typing scores for the three optical nead pointer systems. Data are still being collected (Angelo, 1989). To date, there are few studies on the attitude of a person with disabilities towards high technological adaptive devices. Personal acceptability is defined as the extent to which the consumer is psychologically comfortable in using the device in public or 
private, including the aesthetic attractiveness of the device (Batavia \& Hammer, 1990). Often psychological

comfort is deemed less important in prescribing devices, but if an individual does not feel positive about using the device, it is likely the device will be abandoned. This study is concerned with the subjects' acceptance of the interface device along with how well it operates. Computer users not only judge interface devices by how much they increase function but whether they enhance a user's personal quality of life.

\section{Occupational Therapy Frame of Reference}

The need for the profession of occupational therapy to derive a model of practice and education led to the conceptualization of occupational behavior by Mary Reilly and her graduate students (Reilly, 1969; Matsutsuyu, 1971). Occupational behavior is defined as "that aspect of growth and development represented by the developmental continuum of play and work as they support competence, achievement and occupational role" (Woodside, 1976, p.11). Typical occupational roles as defined by Reilly in 1969 included housewife, student, preschooler and retiree (Reilly, 1969). This frame of reference borrows the concepts of human development, motivation, role acquisition, and socialization from psychology and sociology thus making it a biopsychosocial model (Reed, 1984). 
Some important assumptions in the occupational behavior frame of reference are that: (1) man has a need to master, alter, and improve his environment, (2) achievement can be facilitated and strengthened through play and work, and (3) occupational therapy should focus on a patient's ability to carry on the daily activities required by his social role (Reed, 1984). Illness may result in a decrease of exploratory, competency, and achievement behaviors which are necessary for a person's social roles. In this case, occupational therapy has the task of preventing and reducing incapacities resulting from illness and to activate residual adaptation forces within a patient (Reilly, 1969).

Subjects with spinal cord injuries had a high rate of unemployment $(67 \%)$ and much more daily free time than their nondisabled counterparts (Yerxa \& Locker, 1990). Lack of employment also means more free time, a commodity that was related to lower life satisfaction (Robinson \& Shaver, 1973 cited in Reed, 1984). Many persons with disabilities often experience a reduction or termination of role acquisition and participation in activities (Versluys, 1980). To be without an occupational role is to be without a major social role in this culture (Farker, Brown, Child, \& Smith, 1977 cited in Reed, 1984). Besides dealing with the physical limitations, disabled persons have to suddenly deal with the 
excessive free time they have. It is a great challenge for occupational therapist to help these disabled persons discover alternative satisfying ways to spend time (Yerxa \& Locker, 1990). "The occupational behavior framework illustrates a unique view of adapted computer access methods for word processing" (Sunahara, 1990, p.11). The acquisition of word processing skills can enable disabled persons to complete educational and vocational work, thereby fostering independence and facilitating the role of student and employee (Sunahara, 1990).

\section{Summary}

Occupational therapy has long been involved in the treatment of persons with severe disabilities. Therapists have focused on maximizing the independence of their clients through activities and adaptive equipment. With their training and background in human dysfunction, activity analysis, facilitation techniques to enhance activities of daily living, and rehabilitation technology, occupational therapists are well qualified to train and recommend appropriate specialized computer interface devices for persons with limited use of their hands.

In recent years with the advancement of technology, computers can now be accessible to persons with physical limitations. This accessibility can potentially provide tremendous service to the population of individuals with 
physical disabilities. Educational, banking, employment, and leisure activities are all within closer reach.

Therapists and potential disabled users alike are faced with a wide variety of interface devices that can be operated by head, eye, chin, or tongue movements. There has been very limited evaluation or comparison studies on the performance or acceptability of these interface devices.

Persons with severe disabilities are more likely to experience excessive free time, unemployment, and lower life satisfaction (Yerxa \& Loker, 1990; Robinson \& Shaver, 1973 cited in Reed, 1984). It is a challenge for occupational therapists to assist persons with severe disabilities to accomplish activities within the context of a social role such as a student, parent, and peer. According to the occupational behavior frame of reference, occupational therapy should focus on a patient's ability to carry on the daily activities required by his sccial role (Reed, 1984). 
CHAPTER 3

\section{DESIGN AND METHODOLOGY}

Introduction

This study employed a descriptive case study design to examine the performance of persons with severe physical disabilities on computer input devices. The questions and objectives reflect the purpose of this study to investigate the performance and acceptability of computer interface devices for individuals with severe physical disabilities. The sample consisted of four high school students with diagnoses of Spinal Cord Injury or Muscular Dystrophy. Each subject had limited upper extremity use and a strong interest in learning about different computer interface options. The researcher trained each subject on three different interface devices (Mouthstick, HeadMaster, and Tongue Touch Keypad) and collected data on speed, accuracy, perceived level of exertion, and acceptability. Data were analyzed through descriptive comparisons and visual analysis.

\section{Objectives}

The objectives for this research were:

1. To explore the input speed and accuracy in performance by persons with severe physical disability for three computer interface devices. 
2. To examine the attitude of persons with severe physical disabilities toward specialized computer interface devices. 3. To generate data that will be used to aid in selection and evaluation of adaptive computer devices.

\section{Research questions}

The research questions to be answered in this study were:

1. What are the input speed, accuracy, and rate of perceived physical exertion of persons with severe physical disabilities on each of the following computer interface devices?

a. Adlib Mouthstick with bend

b. Head Master sip and puff system

c. Zofcom Tongue Touch Keypad

2. What is the attitude of persons with severe physical disability toward the acceptability of each of the three interface devices under training conditions?

subject Recruitment

The following agencies were contacted by telephone to recruit subjects:

California Children's Services, Santa Clara

California Children's Services, San Francisco

Santa Clara Valley Medical Center

Center of Independent Living, Berkeley 
Disabled Student office, University of California, Berkeley

Disabled Student office, Stanford University

The following information was presented to open dialogue: My name is Cynthia Lau, I am completing research for the Master of Science degree at San Jose State University; I am representing Zofcom, Incorporated and Foothill college. We would like to recruit physically disabled individuals between the ages of 17 and 21 for an Adaptive computer class to evaluate specialized computer interface devices. The individual must have a severe physical disability involving all four extremities, good oral motor control, and vital capacity to participate in this class. In exchange, the student will have the opportunity to take a college class, tuition free, and receive instruction on computer technology that may help him or her with future educational goals. Do you know anyone at your agency who may be interested in this class?

\section{sample}

The sample consisted of four students with severe physical disabilities who enrolled in the Adaptive Computer Application class at Foothill college in Los Altos which was sponsored by grants from the United States Department of Education and Zofcom, Incorporated. Students were recruited from local agencies and schools that serve persons with 
disabilities. Once referred for the class, the candidates were screened by the researcher using a subject Profile for Evaluation conducted by interview. (Refer to Appendix A). All candidates who were selected had a severe physical disability involving all four extremities and were between the ages of 17 and 21 years old. They had the vital capacity needed to operate a sip and puff device by being able to blow enough air into the switch to make a selection. They also needed the oral motor control: tongue tip elevation, retraction, and lateralization necessary for using the tongue switch. They needed to be able to hold a mouthstick in their mouth with a sustained bite for at least 30 minutes before a rest period. In addition, they needed to be able to tolerate an upright position in their wheelchairs for a minimum of 3 hours. They needed to be qualified for a high school education diploma or college entrance exam as well. All of the candidates had varied computer experience but no experience with the two higher technological interface devices, the HeadMaster and Tongue Touch Keypad. One subject used the mouthstick as a page turner and typing stick as part of his rehabilitation. The criteria for subject selection were based on the consent and availability of the candidates. Each subject consented in writing to be a participant and to be available throughout the estimated length of the study (Refer to Appendix B). 


\section{Procedures}

A descriptive case study design was utilized to examine the performance of the subjects on computer input devices. Subjects were given training time, perceived rate of exertion test, speed and accuracy test, and an interview on each of the three devices. The study was conducted as part of the Adaptive Computer Application class at Foothill College in Los Altos, California. The design of this research provided the subjects the opportunity to access, use, and evaluate computer interface devices that can assist them with educational goals. The selected interface devices, software programs, and Macintosh computers utilized in the study were provided by Foothill college and zofcom, Incorporated. The researcher along with the assistance from the Foothill College instructor for the Adaptive Computer Application Ciass trained the students on how to use the devices and recorded the data.

once a student qualified and consented to be a subject in the study, each was given one device on which to train at a time. All data on typing speed and accuracy were recorded on the data collection sheet (Appendix C). To address the learning curve on each of the three devices, students were given a maximum training time of two hours and were required to learn to type a baseline sentence containing letters, numbers, and symbol keys within 15 minutes with 80 percent 
accuracy. The training time required to accomplish this task was recorded. Secondly, the subjects were given typing drills lasting 30 minutes and at every 10 minute interval, ratings of perceived exertion for the computer activity were recorded using the Borg's scale as shown in Appendix D (Borg, 1982). Another 30 minutes was allotted for students to increase proficiency with the interface device, bringing the total training time to approximately three hours on each device. Typing drills were taken from a typing book (Owen, 1976).

Thirdly, three baseline tests $(X Y Z)$ and nine 3 minute speed and accuracy typing tests were given. The results were recorded on the data sheet. All typing tests were from the typing book and the Typing Tutor software program. Sample of the tests are shown in Appendix E. Speed was measured by number of characters typed per minute. Accuracy rate was determined by the number of characters correctly entered divided by the total number of characters entered per minute. Lastly, after the training and testing were completed, a questionnaire composed of a likert-type questions regarding personal acceptability of each device was administered (Appenaix F). $\bar{A} \dot{C}$ the end of the study, subjects participated in an exit interview asking for their personal opinion regarding the content of the study and instructional method (Appendix G). 


\section{Quantitative and Descriptive Technique}

The quantitative data on input speed, accuracy, and perceived rate of exertion for each of the three devices were compiled and charted on bar graphs. For each subject, there was a comparison of performance on each device in terms of input speed, accuracy, and exertion. Data on the level of personal acceptability from the questionnaire on each device was also compiled and graphed. Additional comments made by the subjects while taking the questionnaire were also recorded. To achieve the necessary comparisons, visual analysis of the data were utilized. Information from the student profiles and exit interviews were reviewed for relevant information written up ir a descriptive analysis.

\section{Computer Interface Devices}

on the following pages are descriptions of the three interface devices used in this study. Available model and serial number of the specific hardware and software utilized in this study are included in Appendix $\mathrm{H}$. 


\section{Mouthstick}

The mouthstick is a "low-tech" frequently used computer interface device for people with quadriplegia. The mouthstick (Figure 1) is made of lightweight aluminum and has a rubber bite plate on one end and a bendable distal end that can be adjusted to a desired angle. The cost of the mouthstick is approximately thirty dollars and can also serve as a page turner or can be adapted into a writing device. The person with involvement in all four extremities can hold the mouthstick with a sustained bite and can interface with the computer by using the distal end to type on a standard keyboard. When not in use, the user can place the stick on the docking station which is clamped onto the table without the use of his hands. 
Figure 1

\section{Mouthstick and Computer Station}
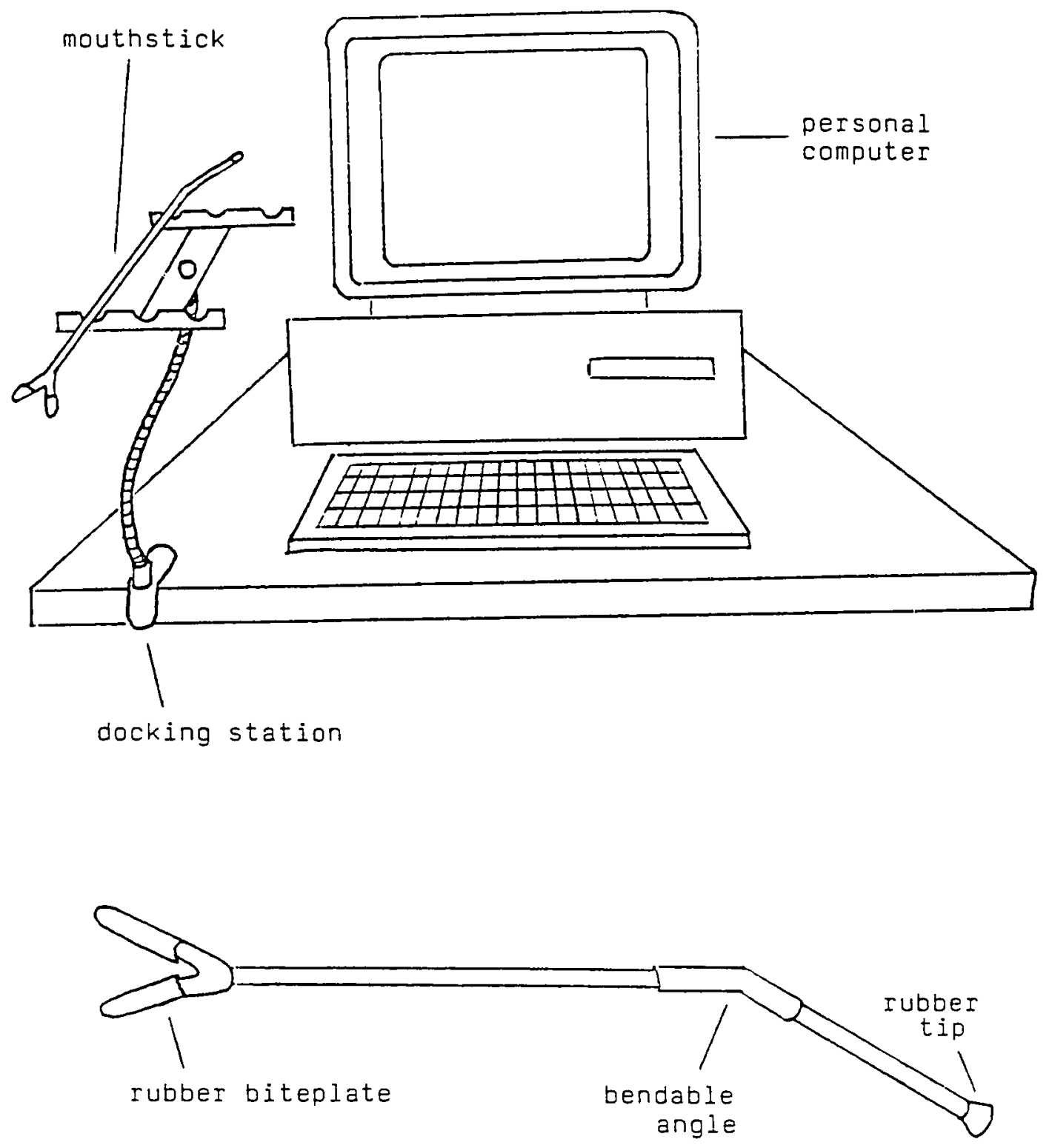


\section{HeadMaster}

The HeadMaster (Figure 2) manufactured by the Prentke Romich Company is another common computer interface device. It is used by adults and children with quadriplegia. It replaces the standard mouse with a lightweight headset. The headset moves the cursor to where the user turns his head to a location on the screen. For this study, the HeadMaster was used in conjunction with WordWriter software for word processing. The subject moved his headset to the desired corresponding position on the screen and then selected characters on the WordWriter video keyboard by blowing air into the puff switch. The technology of this device involves an ultrasonic signal sent from the headset to a control unit which sits on top of the computer. The headset is connected to the control unit with a cable. The user with no hand function required assistance to don and remove the headset. 


\section{Figure 2}

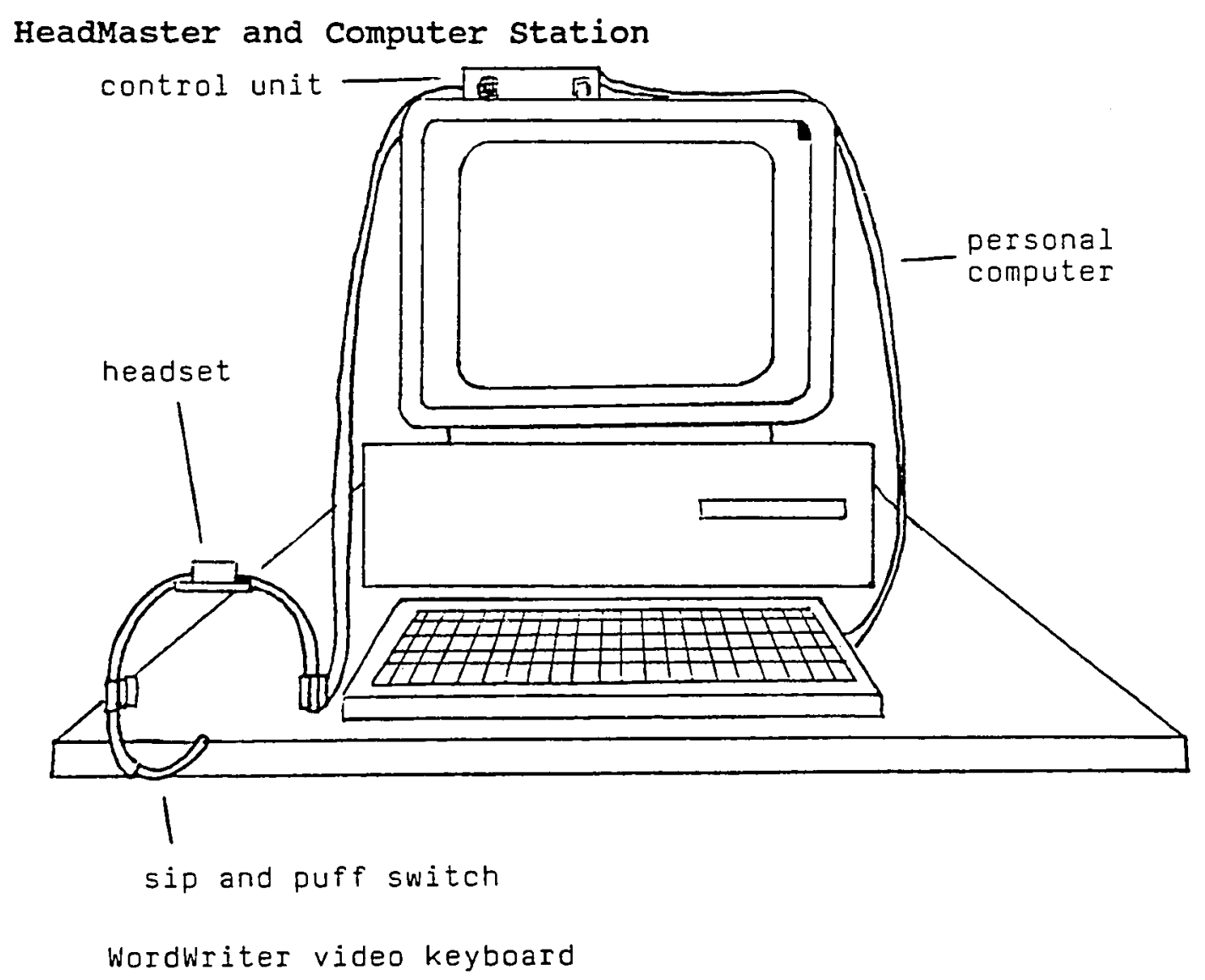

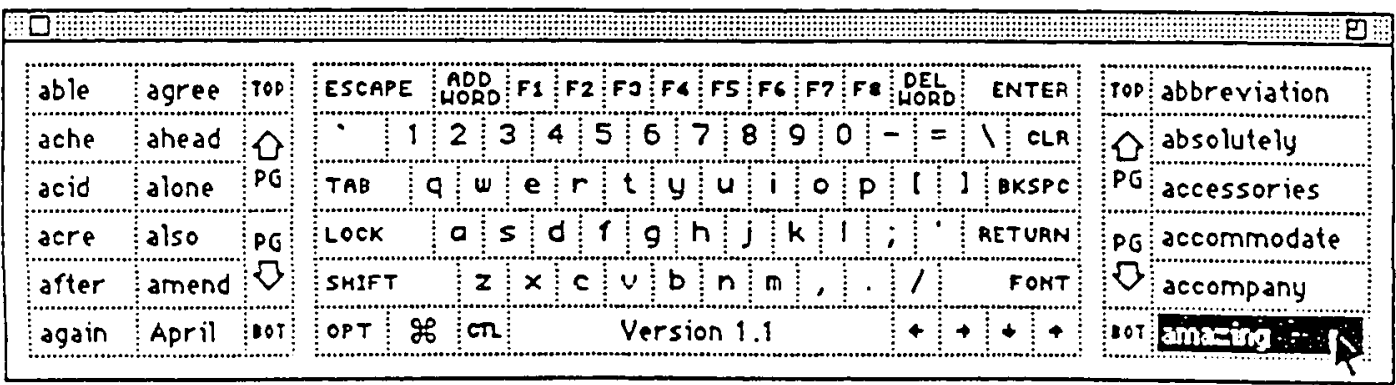




\section{Tonque Touch Reypad}

The prototype Tongue Touch Keypad (TTK) (Figure 3) is a battery operated radio frequency transmitting device similar in appearance to an ordinary orthodontic retainer. It can be customized for use by each individual by a dentist who fits it against the roof of the user's mouth. It contains nine braille keys which are activated by the tip of the tongue tip elevating to the roof of the mouth. When pressed, these keys can activate different pre-programmed equipment in the user's environment such as a computer, television, lights, phone, etc.

The zofcom Controller, attached to the user's wheelchair, received radio signals from the TTK and sent signals to the computer. A small screen display reflected the user's choices. As with the HeadMaster, the subjects could use the TTK as a mouse in conjunction with the WordWriter to select characters on the screen. The tongue is used to press a key that corresponds to a specific direction on the video keyboard. When the cursor is on the desired character, the character is typed by pressing the middle key (number 5) of the TTK. The person without use of the upper extremities required the assistance of the researcher to insert and remove the TTK from the subject's mouth. 


\section{Figure 3}

Tongue Touch Keypad
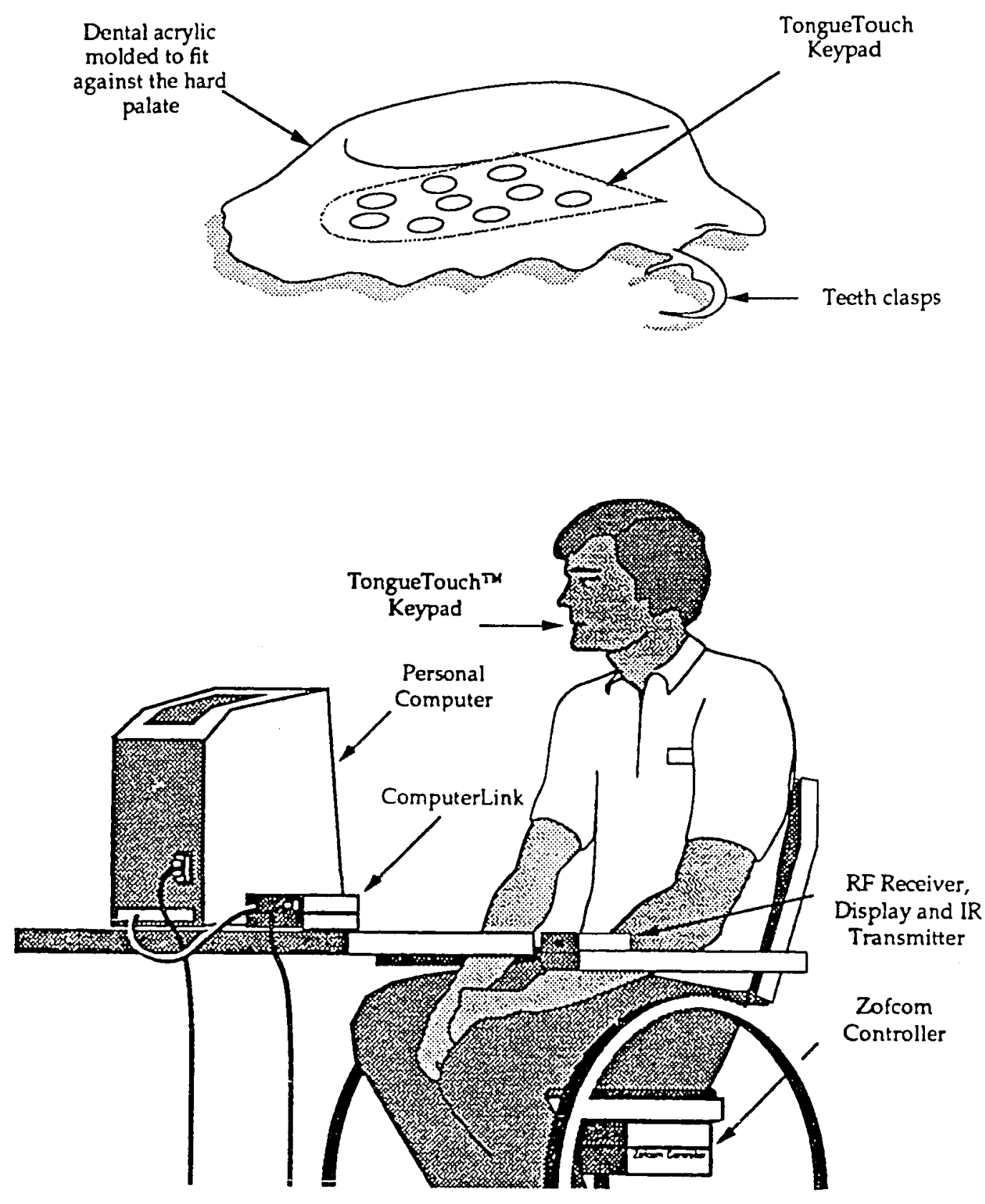
CHAPTER 4

\section{ANALYSIS OF DATA}

Introduction

Data for this study were collected in the Adaptive Computer Application Class which the researcher coinstructed at Foothill college in Los Altos, CA, during the winter semester, 1990. The class and data collection were originally scheduled for six weeks, however, twelve weeks were required due to transportation problems, illnesses and medical appointments of the subjects.

One subject, a 17 year old stanford University student, had to drop out of the study half way through due to the pressure of his regular class work. There was not enough time left in the semester to replace him.

The following analysis begins with a description of each subject derived from the suiject profile (Appendix B), followed by a discussion of each individual's experience in the study, performance, perceived level of exertion, and opinion of personal acceptability of the device.

\section{subject I (Donny)}

\section{subject Profile}

Donny's occupational roles include son and high school student. Donny is an 18 year old high school senior with a medical diagnosis of Muscular Dystrophy-Duchenne. He lives at home with his parents and has attendant care five hours a 
day. His parents are very supportive and encourage him to live life as normally as possible even with the progressively debilitating disease. He has achieved a 3.00 grade point average and aspires to a career in computer programming. During the course of the study, Donny suffered serious respiratory illness that required hospitalization for more than a month. Fortunately, due to his desire to be productive and with the support of his parents, he returned to and finish his participation in the study. Problems that may deter his reaching his occupational goals include illness, daily fatigue, and poor input rate at the computer. Reportedly, Donny has normal vision and hearing, clear speech and complete oral control. His head movements in all directions are intact. Shoulder and elbow movements are absent. He has some weak grade fair forearm pronation. Wrist and finger movements are weak and limited in range of motion. He has difficulty manipulating small objects and performing simple tasks for himself (i.e., scratching his face). Donny cannot move his lower extremities.

Donny can sit in his wheelchair for 12 hours at a time before becoming fatigued. Functionally, he can independently operate his power wheelchair using a joy stick, write legibly with a regular pen, use a speaker phone, and feed himself with his fingers while sitting at a high table. He needs maximum assistance with activities of 
daily living such as transferring from bed to wheelchair, dressing, and bathing by his attendant.

Donny has owned a Macintosh computer for three years and uses it for word processing, spreadsheets, graphics, and games. He uses word processing for school reports and spreadsheets for football statistics. He accesses the computer by laying the keyboard on his lap and typing with his thumbs hilaterally. Reportedly, he types about 20 characters per minute. He enrolled in the Adaptive Computer Application class at Foothill college to learn about alternative computer interface systems that may assist nim in his educational endeavors. As his disease progresses it will become more important for him to conserve his energy. If he could increase his computer speed and accuracy without tiring, he could be more productive in doing all his college work.

Donny's physical condition requires him to operate the computer through his hand or head control. He is currently using his hands but this can be very tiring to the already weak musculature in his upper extremities. Donny could participate on each of the three interface devices because he had good head mobility and oral control.

\section{Performance on the Computer Interface Devices}

During testing, Donny said he felt he could do better when he was not being timed. On the (XYZ) baseline, while 
Donny used his thumbs to interface with the computer, he typed approximately 35 characters per minute (cpm) with high accuracy. He complained that his arms became tired using this method. On all of the three minute typing tests, Donny scored at least 96 percent accuracy with all three interface devices. The method of interface apparently had little to no bearing on the accuracy of input for Donny. Referring to Figure 4, Donny performed the fastest input with the mouthstick averaging about $40 \mathrm{cpm}$. The slowest method was the Tongue Touch Keypad (TTK) with the HeadMaster ranging in the middle. There was a definite change of level from the baseline (XYZ) in comparison to the three interface devices. Donny was able to input approximately 5 more cpm using the mouthstick than using his thumbs alone. The HeadMaster performance was slightly slower than the baseline performance, and the TTK performance was less than half the baseline speed. There appeared to be a slight improvement with the mouthstick speed over the baseline, with a slight deterioration using the HeadMaster, and a substantial deterioration using the TTK.

There seemed to be a curvilinear trend present within the training of each interface device. Over the length of testing on each device, Donny increased his speed up to test number four. After test four, there was a steady decrease of speed. Perhaps, the subject became fatigued after four 3 


\section{DON}

3 MINUTE TYPING TEST

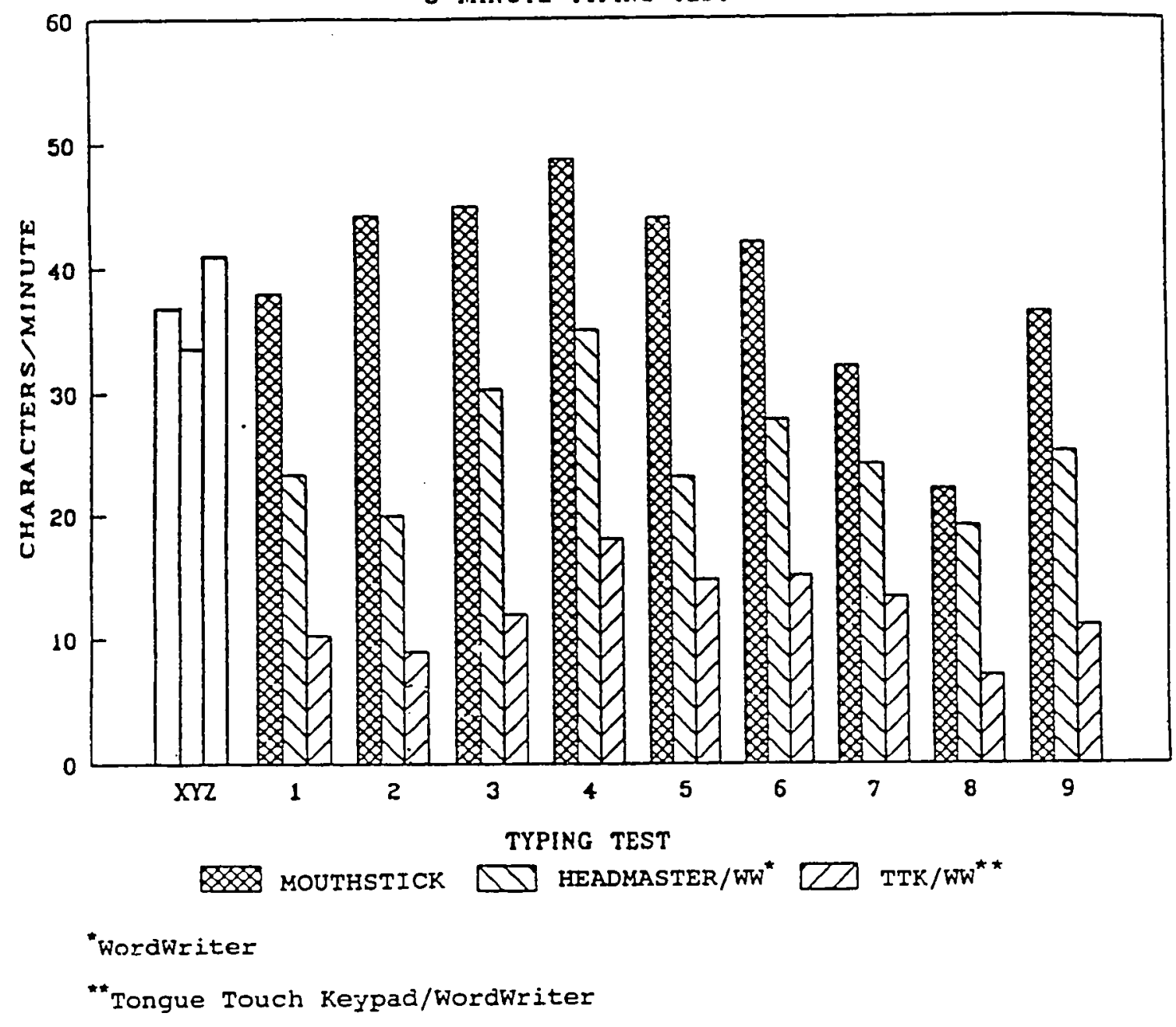


minute tests using the same interface device.

Reportedly, Donny said that typing with his thumbs required rest periods every 5 to 10 minutes otherwise he felt pain in his shoulders. The fatigue ratings (Figure 5), based on the Borg's rate of perceived exertion scale over 30 minutes of activity, showed that Donny's level of exertion increased at a steady pace from 2 to 30 minutes of computer activity on all three devices. Donny rated the HeadMaster the highest in exertion starting at fairly light and ending on hard. Having to use head rotation and lateral flexion to operate the HeadMaster, he complained of neck pain after 20 minutes of continuous use. He also complained of jaw pain from the sustained bite needed to hold the mouthstick after 20 minutes. He rated the TTK the lowest in exertion starting at very light, ending with somewhat hard.

The trend of all three over a 30 minute period was linear in fashion increasing a steady pace over a 30 minute period. If Donny was working on the computer in a natural setting rather than a test situation, he would require frequent breaks to lower the level of exertion and prevent exhaustion using either of the three devices.

\section{Personal Acceptability of the Interface Devices}

Donny rated the TTK highest on personal acceptability (Figure 6) and the mouthstick and Headmaster approximately the same at the neutral level. In was evident from the 
Figure 5

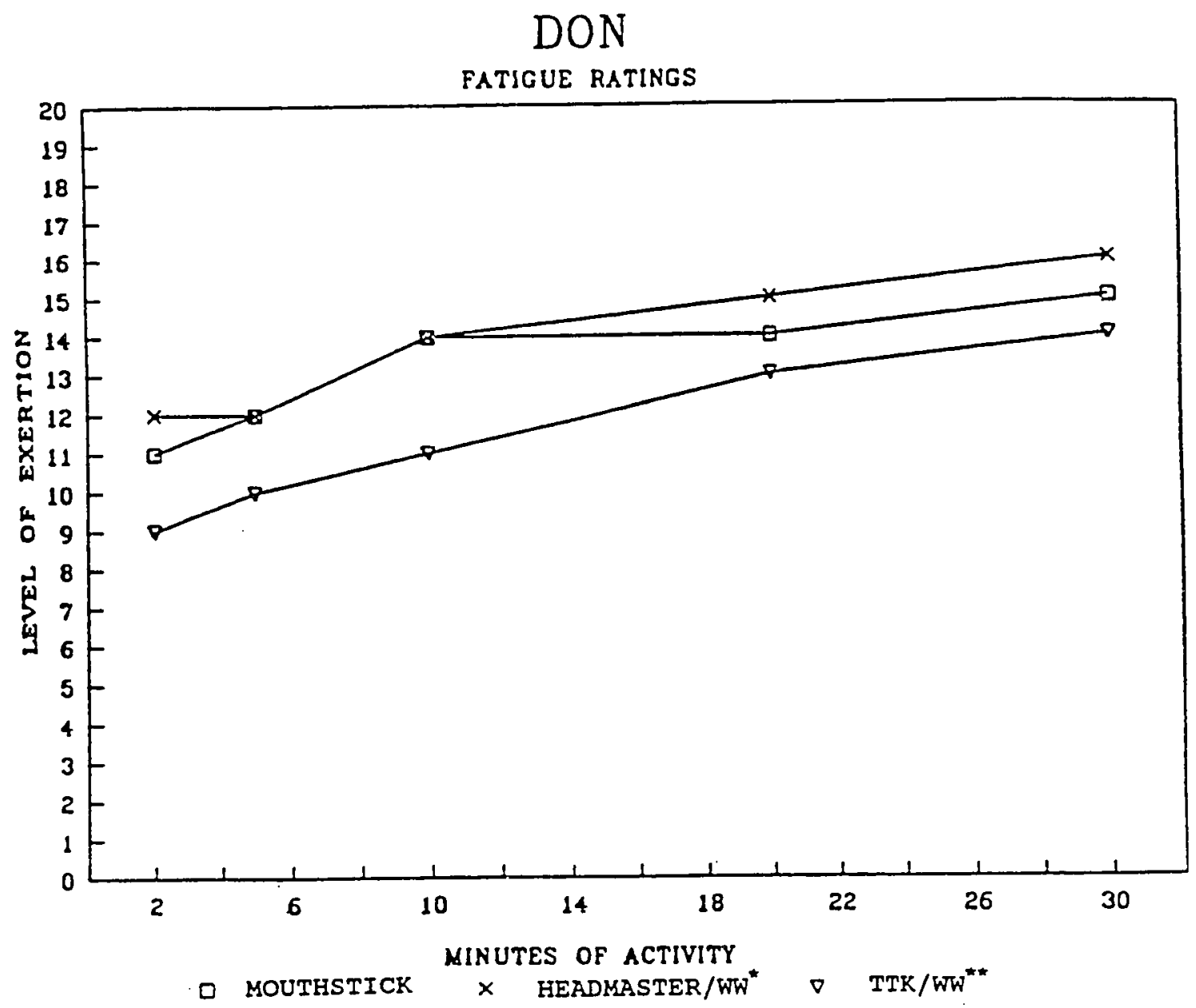

"WordWriter

"tongue Touch Keypad/WordWriter 
Figure 6

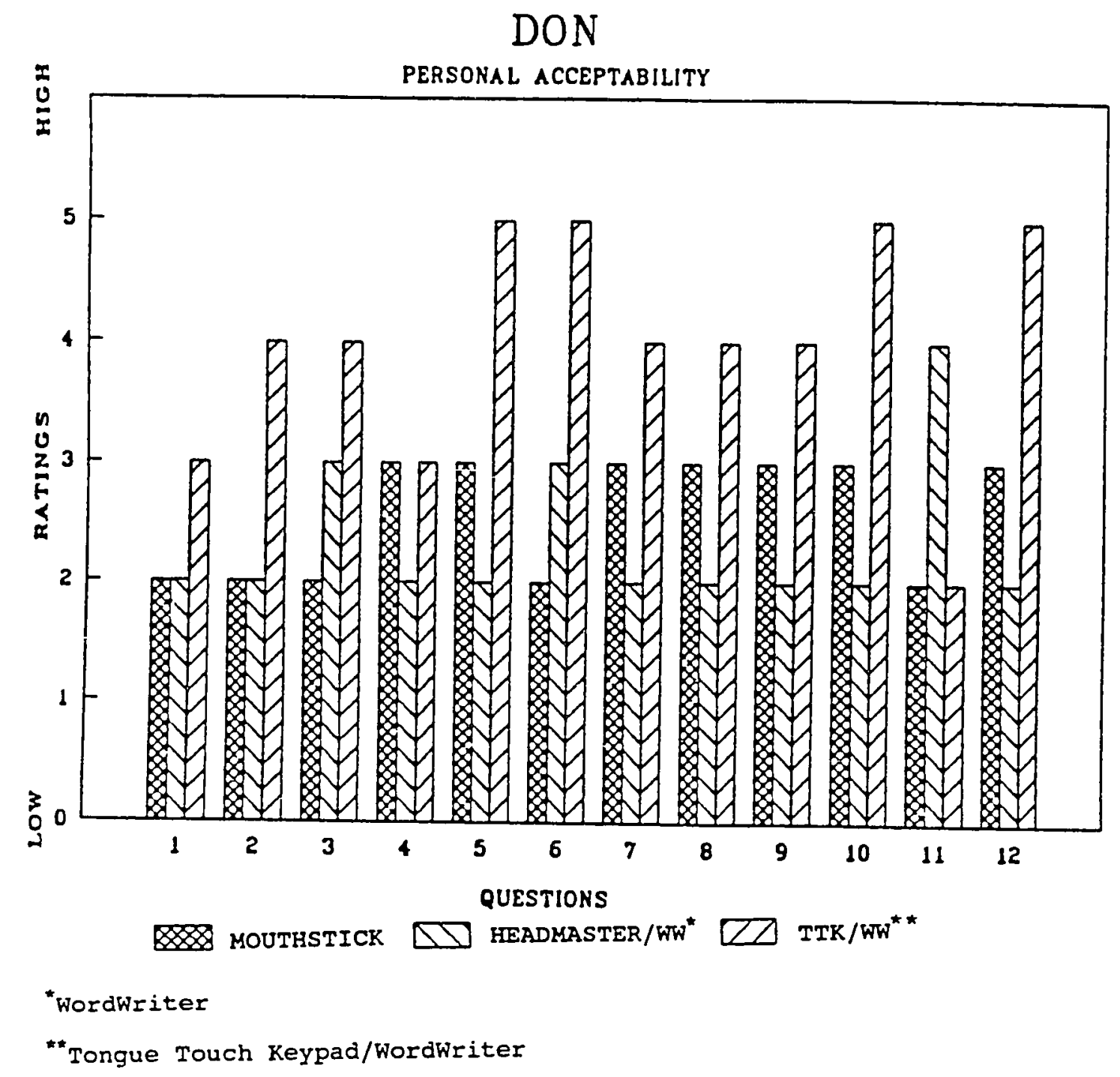


Fersonal Acceptability Questionnaire (Appendix F) data that Donny felt most attractive using the TTK because "no one notices you are using a special piece of equipment." He said "The mouthstick and HeadMaster will attract attention but the TTK would not." Donny reported that he became confused with the different head/movements required to move the HeadMaster therefore he did not feel very productive using it. Donny communicated that both the HeadMaster and mouthstick caused a "strain on the neck" but that the TTK did not. Using the TTK caused the least eye strain for Donny. The mouthstick required the user to consistentiy look intermittently at the keyboard, typing material and the computer monitor. The HeadMaster and TTK eliminate the use of the standard keyboard by using the WordWriter video keyboard on the computer monitor. On the other questions, Donny rated using the TTK as being the least strain on the mind and being most desirable for his personal use. Although Donny liked the TTK best for personal use, it interfered with speech as did the mouthstick. While biting on the mouthstick, Donny could only produce garbled speech and while wearing the TTK, he had slightly slurred speech. overall, Donny liked the TTK best of the three devices.

\section{Exit Interview}

Donny and his family were very enthusiastic about the class/study. Since Donny is expecting to apply for college 
next fall, he was ambitious to look for a computer interface device that may replace the use of his weak hands. He also missed one month of the class due to illness and hospitalization. There was no pressure for him to return to the study but he chose to do so. He expressed wanting to finish what he started and also to increase his knowledge of computer interface devices. Donny said that it gave him a great sense of accomplishment to complete the class/study. of the technology covered, Donny rated the TTK highest because of its comfort and aesthetic value. But it was also the most difficult computer interface to learn because elevating the tongue to the roof of the mouth in order to activate a key was a new concept. The mouthstick and HeadMaster were easier to learn but caused either jaw or neck pain. Donny would like to practice and use the TTK for his own personal use.

\section{subject II (Ernie)}

\section{subject Profile}

Ernie's occupational roles include son, high school student, volunteer, and uncle. He is a 20 year old bilingual (Spanish and English) high school senior. He acquired a spinal cord injury at the c5-6 level in 1985 from a gun shot wound. He lives at home with his mother and a large extended family. After his injury, he went through a 
long period of depression marked by anorexia and suicidal behaviors. Reportedly, he has adjusted his attitude concerning his physical condition and future and has had a more positive outlook over the last few years. Ernie achieves fair grades at school and hopes to attend college to learn more about computers. He volunteers for the American Cancer society doing data entry in order to gain vocational skills. Potential problems that may interfere with Ernie's goals include illness, chronic neck pain, family issues, and poor performance on the computer.

Ernie has normal vision and hearing, clear speech and complete oral control. He has complete movement at his neck but occasionally suffers from soreness due to the previous injury. At the c5-6 spinal cord injury level, he has weak but functional shoulder movement, elbow flexion, forearm supination, and wrist extension. He has no forearm pronation, wrist flexion, or hand movement. There is also total paralysis of the trunk and lower extremities. Ernie can sit in his wheelchair for eleven hours a day without fatigue. He has no history of pressure sores. Functionally, Ernie can do many tasks for himself. He can independently drive his power chair for mobility and use a standard push button phone. He operates household items such as a VCR, television, and bed by remote control. He writes with a writing orthosis attached to his flexor hinge 
splint and can feed himself with a fork attached to his splint. However, Ernie needs his family to help with daily living activities such as dressing, teeth brushing, and bathing.

Ernie's first exposure to computers was during this past year in school. Presently, he is using an Apple computer to do data entry work for the American Cancer Society. He has been interfacing with the computer by using his writing orthosis (pen with a attachment) secured to his flexor hinge splint to hit the keys on the standard keyboard one at a time. Ernie complained that prolonged periods of working on the computer in this manner with a supinated right arm led to pain in his shoulder. In addition, he could not input very quickly because he had to move his arm over the keyboard with every stroke.

Ernie enrolied in the Adaptive Computer Application class at Foothill college because it allowed him the opportunity to take an introductory college class once a week and still maintain the support of his regular high schocl staff. He had never tried any alternative computer interface devices, but became interested when he realized that they could help him in attaining possible vocational goals.

With the absence of hand function, Ernie needs to use a writing orthosis hooked to his flexor hinge splint to 
interface with the computer. This method seemed fairly effective but was considered cumbersome and tiring at the shoulder after prolong periods of work. Ernie could participate on each of the three interface devices since they did not require any upper extremity movement which caused fatigue.

\section{Performance on the Computer Interface Devices}

on the (XYZ) baseline, Ernie used two pens attached to flexor hinge splints as writing and typing orthoses. He could input approximately 40 characters per minute (cpm) with an accuracy level of 100 percent. He complained that his shoulders would be painful after working on the computer with supinated arms for a hour. On all 27 typing tests, Ernie scored at least $92 \%$ accuracy. Ernie chose a pace that allowed few errors. Referring to Figure 7, Ernie performed the fastest input using the mouthstick with approximately $40 \mathrm{cpm}$, with HeadMaster and TTK coming in far behind. There was an unstable change of level between the (XYZ) baseline and the mouthstick. Among the nine typing tests for the mouthstick, Ernie scored between 20 to $50 \mathrm{cpm}$; this wide range may be due to the fact that Ernie complained of progressive neck pain while using this device resulting in a curvilinear trend. Even given its unstable quality, the mouthstick seemed most comparable to the baseline score in terms of speed of input. Referring to Figure 7, the 
Figure 7

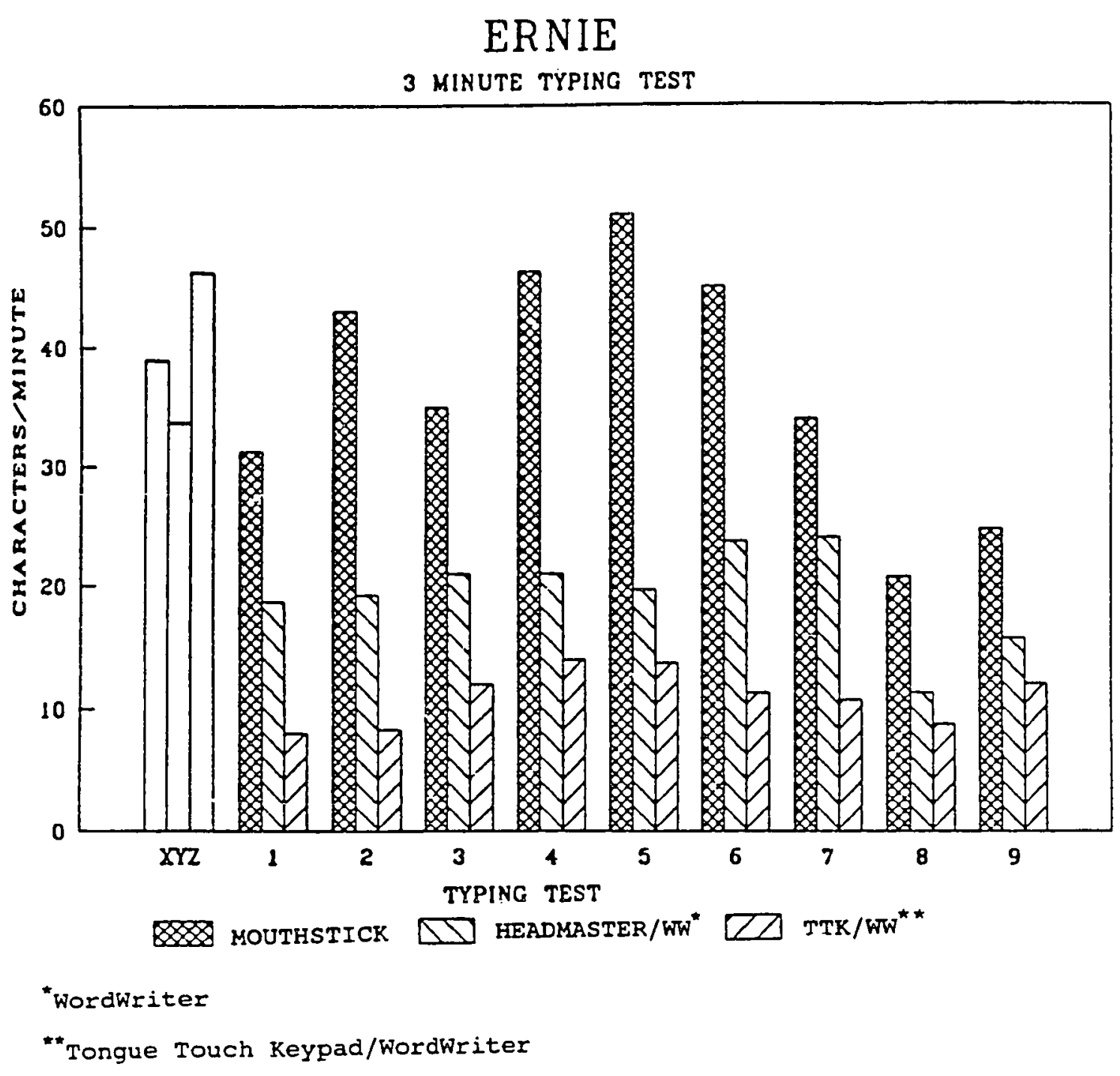


HeadMaster performance was much slower for Ernie averaging about $20 \mathrm{cpm}$ and the TTK even slower at $12 \mathrm{cpm}$. There would appear to be an unstable change between the baseline and mouthstick and deterioration of speed with the HeadMaster and substantial deterioration of speed with the TTK.

Ernie's fatigue ratings (Figure 8) based on the Borg's rate of perceived exertion scale over 30 minutes of word processing activity showed that the his level of exertion increased slightly from 5 minutes to 30 minutes on all three devices. Ernie rated the TTK as the most difficult in perceived exertion starting out at very light exertion and ending at fairly light after 30 minutes of continuous use. When questioned about this rating, Ernie explained that he rated the TrK higher in eyertion as it required greater mental concentration than the other two devices. He rated the HeadMaster requiring the second most physical and mental concentration ending at a light exertion rating. Even though he previously complained of neck pain using the mouthstick, he rated it as requiring the least amount of exertion, ending at very, very light exertion after 30 minutes of word processing. He did not complain about the sustained bite on the mouthstick as being a physical discomfort. The trend of performance on all three devices was linear with a slight upward change in slope towards fatigue over the 30 minute test period. Ernie commented 


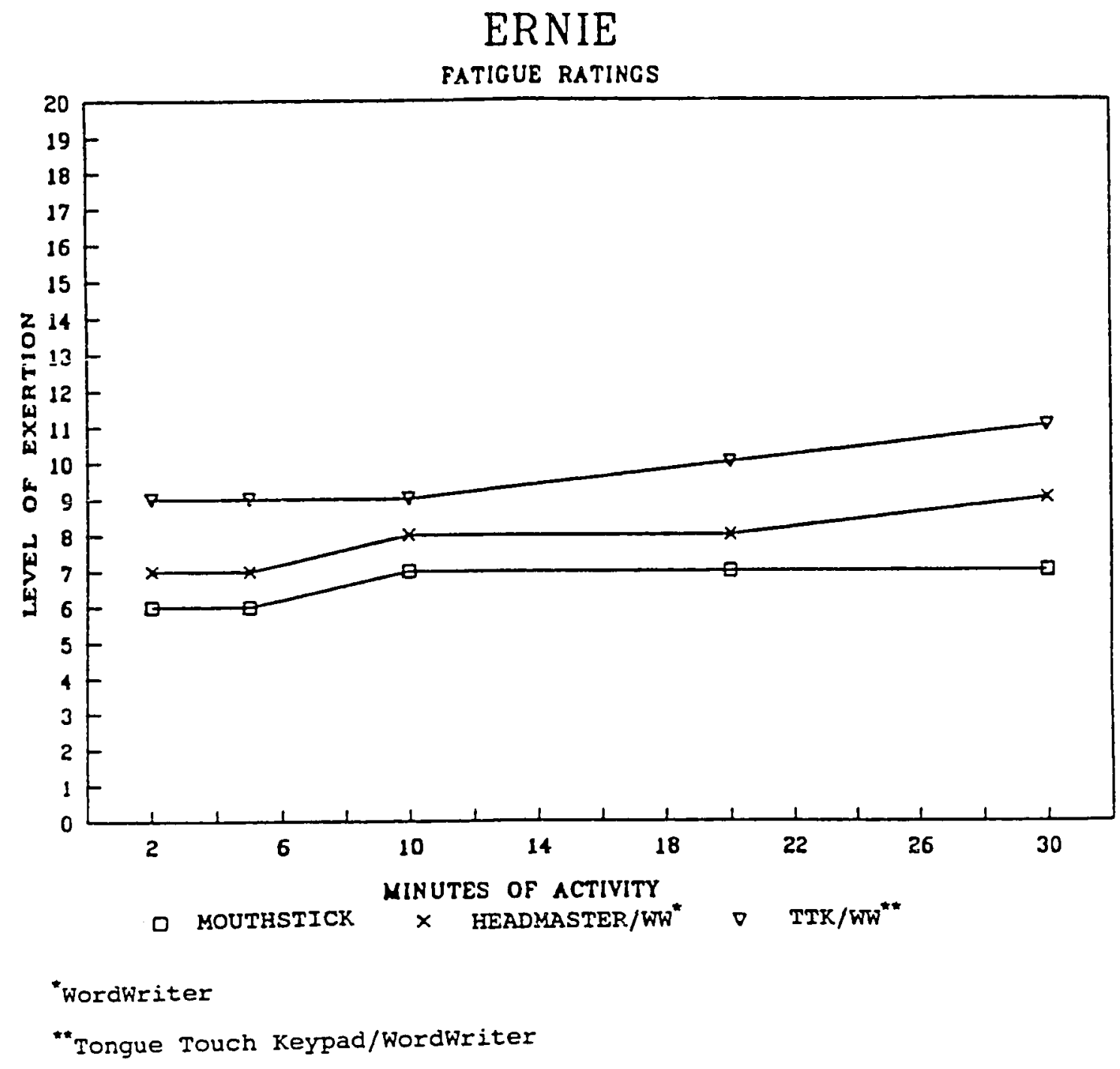


that all thrce interface devices were fairly easy to use and that they were less tiring then his current method of input. Personal Acceptability of the Computer Interface Devices

Ernie rated all three devices personally acceptable above the neutral level (Figure 9). The mouthstick was rated slightly below the HeadMaster and TTK. On the Personal Acceptability Questionnaire (Appendix F), Ernie rated the mouthstick as unattractive even though the rate of input was highest with it. The subject felt equally productive using the three interface devices. Although the TTK required the most mental exertion, performing with the mouthstick and HeadMaster caused physical discomfort for Ernie. Ernie complained that the site of his old gun shot injury caused his neck to be occasionally sore thus making it difficult for him to assess whether the pain in his neck was the chronic pain he usually experienced or was caused by using the interface devices. Invariably, it would appear that using the HeadMaster especially aggravated the subject's neck pain. Ernie communicated that both the mouthstick and TTK interfered with his speaking ability. The mouthstick caused him to speak incoherently. The TTK caused him to speak slightly slower in order to pronounce clearly. Given the drawbacks of using each device, Ernie thought each device had the potential to enhance his 


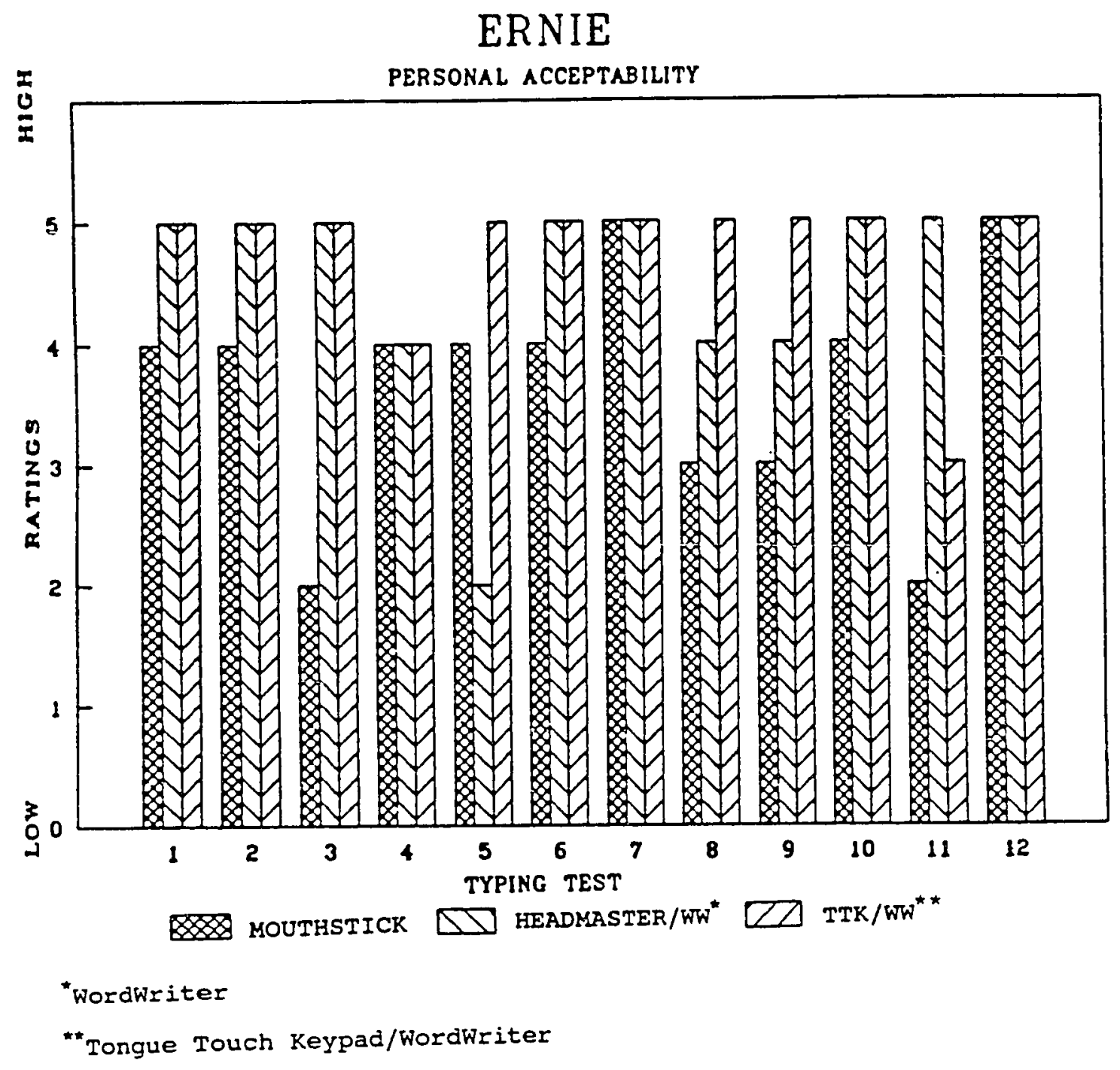


independence and he wanted all three for his own personal use.

\section{Exit Interview}

Ernie had a very positive experience with the study. His family and teacher noticed an apparent increase of selfesteem once the study started at Foothill college. Ernie received a great deal of attention for his initiative in taking a college level computer class. No one in Ernie's family had ever attended college and they were very proud and supportive of him. His high school teachers reported that Ernie seemed to be happier with himself and more confident among his peers.

Ernie liked everything about the Adaptive Computer Application class from the technology covered to the instructionai method provided. He enjoyed learning about different interface devices he could use in lieu of typing with his writing orthosis with splints. None of the demands made in the class/study were difficult to meet for Ernie. He became ill during the course of this study and subsequently missed work but came back and made up the time. Given the opportunity, Ernie would use any of the three interface devices in the study to supplement his current method of interfacing with the computer. All three devices gave his arms a relaxation break since they only required head movements, respiration, or tongue movements. 


\section{subject III (8am)}

\section{Subject Profile}

Sam's occupational roles include those of older brother to three siblings, son, and high̀ school student. In July 1990, seven months before this study, Sam suffered a spinal cord injury at the $\mathrm{c5}$ level from a diving accident. Sam is a 17 year old high school senior. After 4 months of intensive rehabilitation, sam returned home to live with his family. At the time of this study, he did not return to school but received private tutoring at home. His parents reported that he is adjusting well to his disability. Sam hopes to return to high school gradually and apply to a college that has supportive services for students with disabilities. His family is extremely supportive of Sam's goals. Potential problems that may deter his goals include financial issues, psychological adjustments to a severe physical disability, and ineffective use of the computer.

Sam has normal vision and hearing. His tongue movement and oral control are intact. At the time this subject profile was taken, Sam still wore a halo that restricted his head movements. By the time the data collection began, the halo was removed and he had all head movements available. At the shoulder, sam only had 90 degrees of shoulder flexion and abduction. Elbow flexion is intact but he has no elbow extension. Forearm movement is limited to supination with 
no pronation. Sam has no wrist movements, and complete paralysis of the trunk and lower extremities.

Sam can sit in his wheelchair up to 12 hours without fatigue. When not in the wheelchair, he spends his time on the couch or in bed. Since his injury less than a year ago, Sam has striven to be as independent as possible. He drives his power chair for mobility, uses a speaker phone, writes with a universal cuff writing orthosis, and plays Nintendo games with a special adapted joy stick. He requires attendant care five hours a day for dressing, bathing, transfers, and feeding.

Sam has owned a Macintosh computer for the last three and a half years. He uses it for word processing, graphic arts, and recreational games. Before his accident, he had not learned touch typing and used two fingers to type. Post injury, sam uses two pens attached to universal cuffs on each hand to hit the keys of a standard keyboard. Sam is not very comfortable keeping his wrist in the neutral position required by the universal cuff to interface with the computer. In addition, he was not satisfied with the speed of this method.

With family encouragement, sam enrolled in the Adaptive Computer Application Class at Foothill. Even though his injury was fairly recent, his family was very enthusiastic about investigating possible support services 
that would help his adaptation to his disability as well as increasing educational/vocational possibilities. Given that he is a young man with a need to be independent from his family, the class was a good opportunity for him to be with peers who have disabilities and to participate in learning activities without the supervision of his parents. Sam wanted to take the class and participate in the study because it allowed him to develop more control of his life and structure for his free time.

Without hand function, Sam is required to use an external aid to interface with the computer. In this instance, he uses two pens attached to universal cuffs, one on each hand, to activate the keys on the keyboard one at a time. This method is both cumbersome and tiring because it requires sam to use his weak shoulder muscles. Sam was an appropriate candidate for the study because of his strong interest in investigating options that may help him become more independent on the computer.

\section{Performance on the computer Interface Devices}

During the (XYZ) baseline tests, Sam was able to input approximately 25 characters per minute (cpm) with 100 percent accuracy using pens attached to universal cuffs bilaterally. He complained that this computer interface method was both ineffective and cumbersome. On all of the 3 minute typing tests using the three separate interface 
devices, Sam scored at least 96 percent accuracy. He was perfectionistic during testing and became noticeably upset when he made a error. Sam performed the most efficient input rate with the mouthstick averaging approximately 38 cpm (Figure 10). Performance with the HeadMaster came in second with approximately $24 \mathrm{cpm}$ and the TTK last at about $17 \mathrm{cpm}$. There was a definite change of level between the baseline and use of the mouthstick; sam consistently performed faster with the mouthstick than with his previous baseline method. There was not much change of level between the baseline and performance with the Headmaster, making the HeadMaster another possible alternative in terms of adequate input speed. There was a slight decrease of speed level from the baseline to using the TTK. Along each set of 9 tests for every device, sam had unstable performance but within a generally predictable range. There would appear to be a substantial improvement in speed for the mouthstick over the baseline, no substantial change with the HeadMaster, and a slight deterioration of speed using the TTK.

The fatigue ratings (Figure 11) based on the Borg's rate of perceived exertion scale over 30 minutes of activity displayed Sam's level of exertion as increased at a slow pace from 2 to 30 minutes. He rated using the mouthstick and TTK the same starting at "very, very, light" exertion 
Figure 10

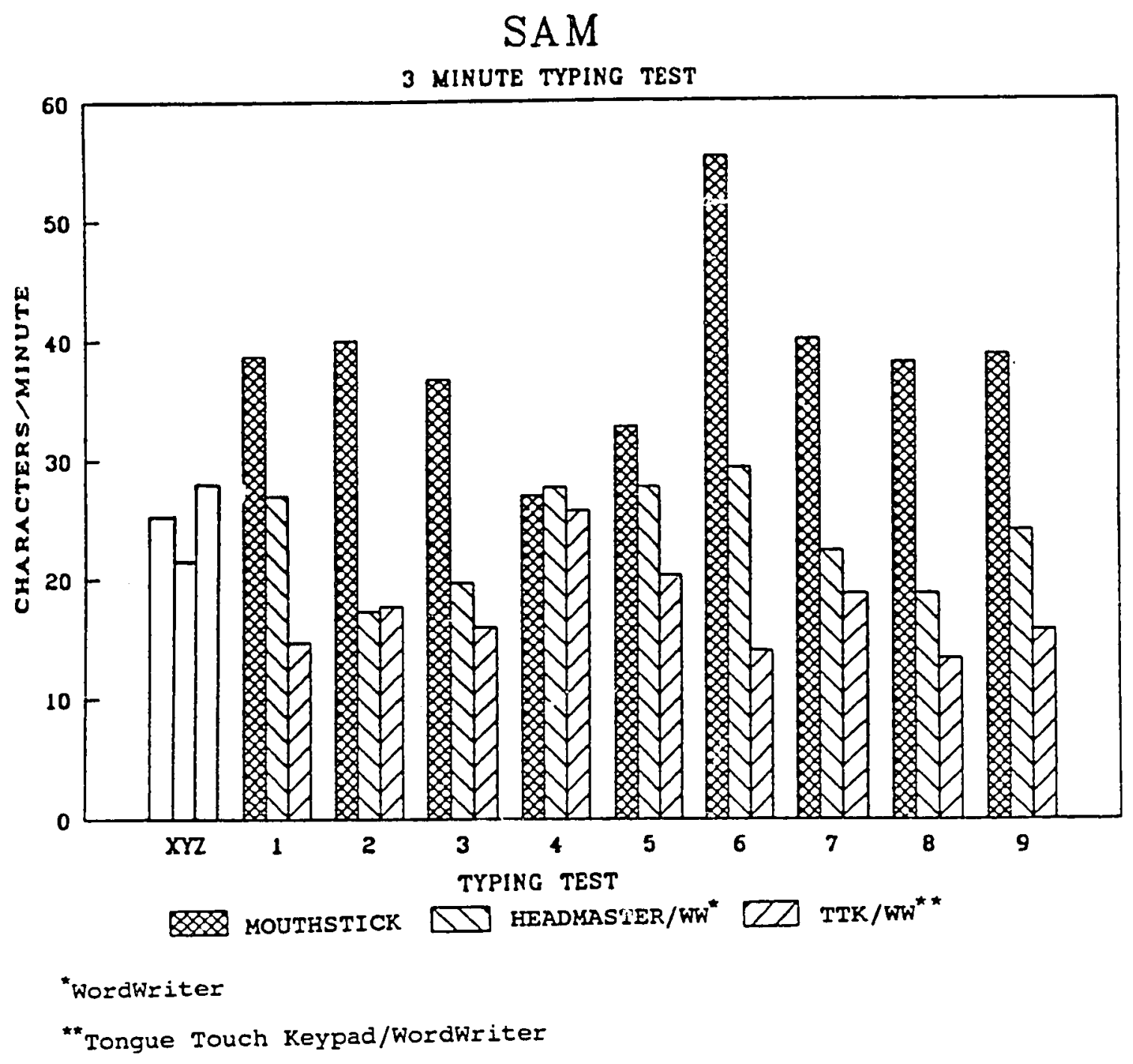


Figure 11

SAM

FATIGUE RATINGS

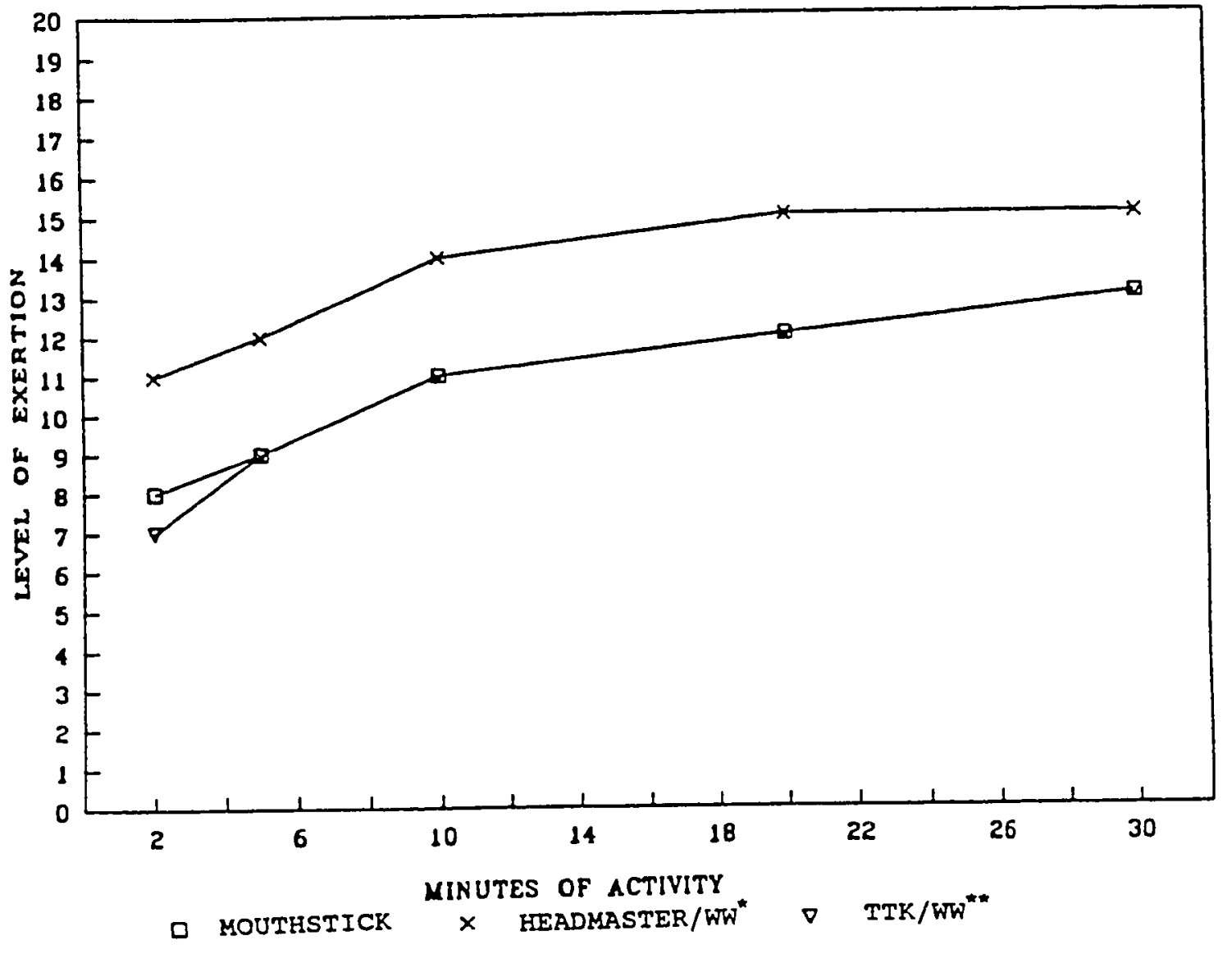

"WordWriter

"Tongue Touch Keypad/WordWriter 
and on "somewhat hard" exertion after 30 minutes of typing activity. The HeadMaster was harder to use requiring more exertion from the start for sam. His first rating was "fairly light," ending with "hard" after 30 minutes.

He rated the HeadMaster as requiring more exertion because he found moving $h$ is head in lateral flexion and rotation on a continuous basis to be tiring. In addition, Sam complained that the headset of the HeadMaster was too tight and uncomfortable to wear for more than a few minutes. The mouthstick also required head movements but only in a slight flexion and extension pattern. overall, all three devices were relatively easy for sam to use given frequent short rest periods.

\section{Personal Acceptability of the Computer Interface Devices}

Sam rated the TTK by far the highest in personal acceptability with the mouthstick and HeadMaster rated slightly below neutral level (Figure 12). From the questions, it was clear that sam only felt happy, comfortable, and attractive using the TTK. Sam deemed the HeadMaster extremely uncomfortable to wear due to the tightness of the headset and the mouthstick being uncomfortable due to jaw discomfort from the sustain bite needed to hold it in place. Since sam's injury was relatively new, his body image was still adapting and he was sensitive to not looking physically disabled. From the 
Figure 12

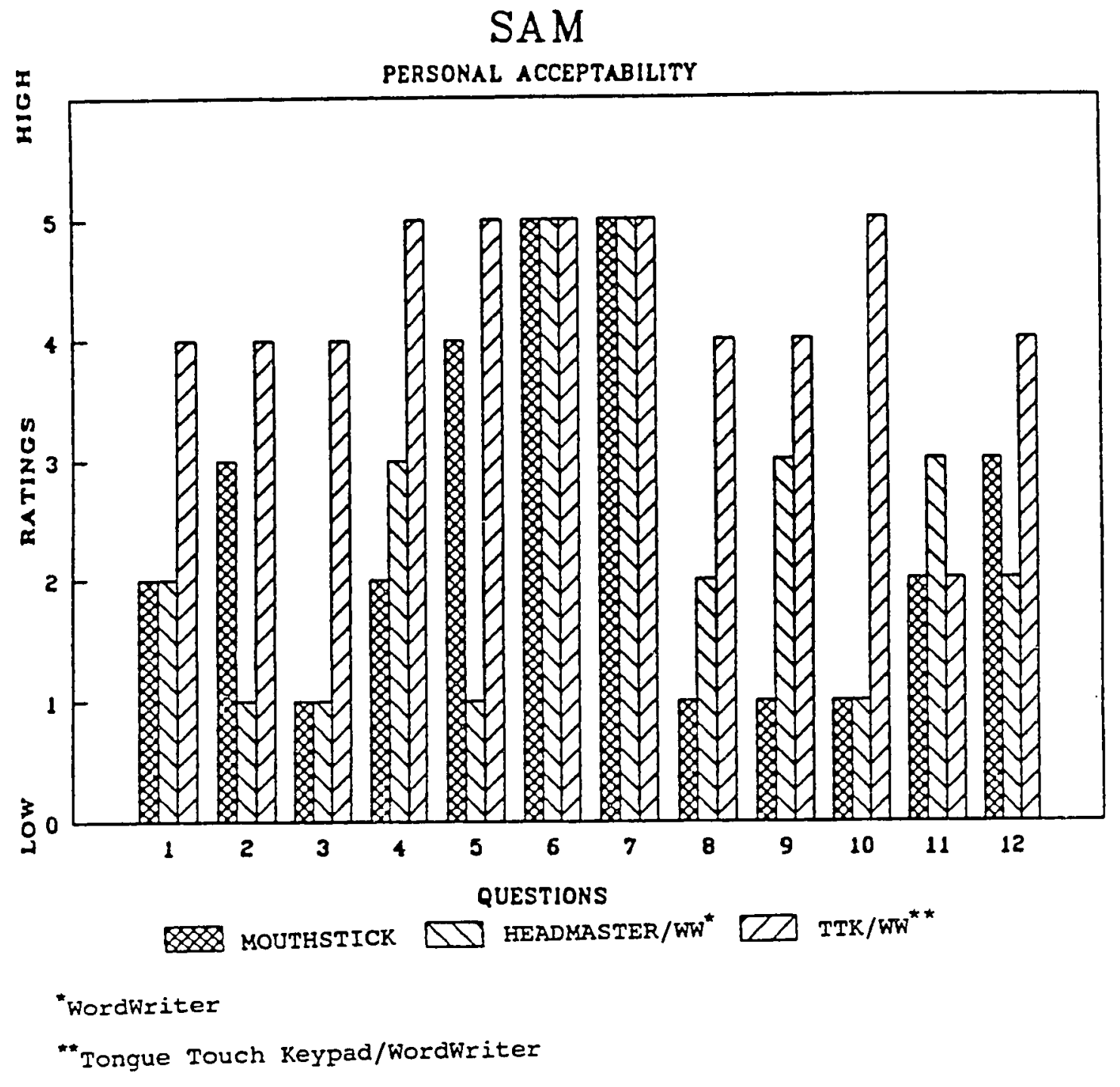


Personal Acceptability Questionnaire (Appendix F), Sam clearly stated that he thought he only looked attractive using the TTK because it was an intraoral wireless device. It was interesting to note that sam reported feeling the most productive with the TTK even though he had the slowest input rate on this device. He repeated that the HeadMaster caused discomfort in terms of neck pain. Sam further reported that none of the devices caused physical strain to the eyes or mental strain. Sam rated the HeadMaster the most uncomfortable but the only device of the three that did not interfere with speech. Sam was the only subject who could speak fairly clearly even with the mouthstick in his mouth. The TTK only had a slight effect on his speech to which Sam quickly adjusted. It was clear from the data that Sam preferred the TTK for his personal use for its low profile and physical comfort level.

\section{Exit Interview}

Sam's family was very grateful for the opportunity to participate in this study as part of the Adaptive Computer Application Class at Foothill college in Los Altos. They had no apprehensions about sam requiring more time to readjust to his injury and they believed that he needed to be involved and productive outside the home environment. sam admitted that he was a little nervous at first but once he met another subject with a spinal cord injury, he relaxed 
and enjoyed himself.

Sam enjoyed the technology, instruction, and social interaction of the study. He said it was a positive experience for him to meet other high school students with severe physical disabilities and inquire about their life styles. He liked the TTK best because he felt the "most normal" using it. While using the HeadMaster or mouthstick in a public setting, other people would know he could not use his hands anymore. The class/study met his expectations because it introduced him to interface devices that he would otherwise not have known about. Now he and his family can decide the equipment in which to invest so that Sam can maintain his skill level on the computer for school work and recreation.

\section{subject IV (Hichael)}

\section{Bubject Profile}

Michael is a 20 year old high school senior who lives with his mother. Michael has the occupational roles of son, uncle, high school student, choir leader, and artist. He has lived all of his life with the diagnosis of Muscular Dystrophy-Duchenne which involves progressive muscle atrophy. His mother is extremely supportive of Michael's being active $i \bar{n}$ the community as long as possible. Reportedly, Michael has a learning disability that limits 
his reading ability at the second to third grade level. The educational staff at Michael's school reports that he is very articulate and artistic. Even with his learning and physical disability, Michael is a talented artist who has won local awards for his drawings. Michael hopes to remain active in his community and pursue art at the college level after high school. He hopes to learn to perform more art related work on the computer. Some issues that may interfere with his goals include illness, financial problems, lack of reading ability, and poor knowledge or use of the computer.

Michael has normal vision and hearing. His tongue movement and oral control are intact and he can move his head through a full range of motion. Upper extremity movements are severely limited. He has no shoulder movements and fair elbow flexion and extension with poor forearm and wrist movement. His right hand is stronger than his left but both hands are limited to a weak prehension pattern made of fair flexion and extension movements. He cannot flex or rotate his trunk without falling over.

Michael can sit in his wheelchair up to 12 hours without tiring. When not in his chair, he spends his time in bed. Michael drives his power wheelchair for mobility in the community. At home he independently operates the television and stereo by remote control. He plays Nintendo 
games by using his thumbs bilaterally. He is able to write and draw by using a right lateral prehension to hold a pen. He uses thumb movements for activities throughout the day, which can be tiring at times. He can feed himself with his fingers while sitting at a high table. He drinks from a straw or a cup held for him. Michael weighs approximately 200 pounds and requires an attendant to take care of activities of daily living such as transfers from bed to wheelchair, dressing, and bathing.

Michael's first exposure to computer technology was at school two years ago. Before this study he had not tried any specialized computer interface devices and was relying on the standard keyboard. He used the Apple computer at school for some word processing, graphics, and games. His favorite application on the computer is art work. To type on the keyboard, Michael holds a pen with a right lateral prehension to depress one key at a time. For art work, he primarily uses the mouse by pushing it with weak elbow and wrist movement. Michael uses his limited upper extremity movement to interface with the computer; this can be very fatiguing and frustrating at times. With continuing muscle atrophy, Michael will need to find alternative ways to interface with the computer.

Michael's mother was very supportive of him participating in this study as part of the Adaptive Computer 
Application class. She recognizes the importance for Michael to be involved in his community and educational alternatives. Michael was very excited about taking a computer class on a college campus. In addition, Michael wanted to investigate computer interface options that would allow him to work on the computer for a longer period of time without fatigue. With progressive weakening of Michael's remaining upper extremity musculature, he will need a head control interface in the near future. He currently uses a pen held in a right lateral prehension to type on the computer. This method is slow and tiring. Michael was appropriate for this study due to his current functional level and future prognosis. He will need to inves of the computer without the use of his hands.

\section{Performance on the computer Interface Devices}

on the (XYZ) baseline, Michael was able to input approximately 13 characters per minute (cpm) with $98 \%$ accuracy using a pen to hit the keys. Michael was slow in word processing due to his unfamiliarity with the keyboard and/or to his reading and learning disability. Michael's baseline method of hitting the keys with a pen one at a time was very slow and did not work well for him. On the 3 minute test, there was some slight variability in accuracy between the 3 interface devices. The lowest accuracy rating 
achieved on each device was 92 percent with the mouthstick, 94 percent with the HeadMaster, and 73 percent with the TTK. overall, the difference in accuracy of input between devices was not substantially significant but there did seem to be a slight decrease of accuracy when Michael used the TTK.

In terms of speed, Michael's performance with the mouthstick was comparable to the baseline with approximately $13 \mathrm{cpm}$. The HeadMaster was slightly slower for Michael at about $9 \mathrm{cpm}$ and the TTK considerably slower at $2.3 \mathrm{cpm}$ (Figure 13). Michael was given an additional hour of practice with the TTK than were the other subjects. There was no change of speed level between the baseline and use of the mouthstick, a slight deterioration between the baseline and use of the HeadMaster and a substantial deterioration between the baseline and use of the TTK. Michael performed very slowly with a pen held in his hand and equally slowly with the Mouthstick and HeadMaster. It was difficult for Michael to build speed with the TTK because he had trouble localizing the keys with his tongue to activate the characters on the video keyboard. Michael claimed that he could perform better on the interface devices if he was not being directly observed and timed. It was the observation of the researcher that he performed equally with or without timed tests.

The fatigue ratings (Figure 14) based on the Borg's 
Figure 13

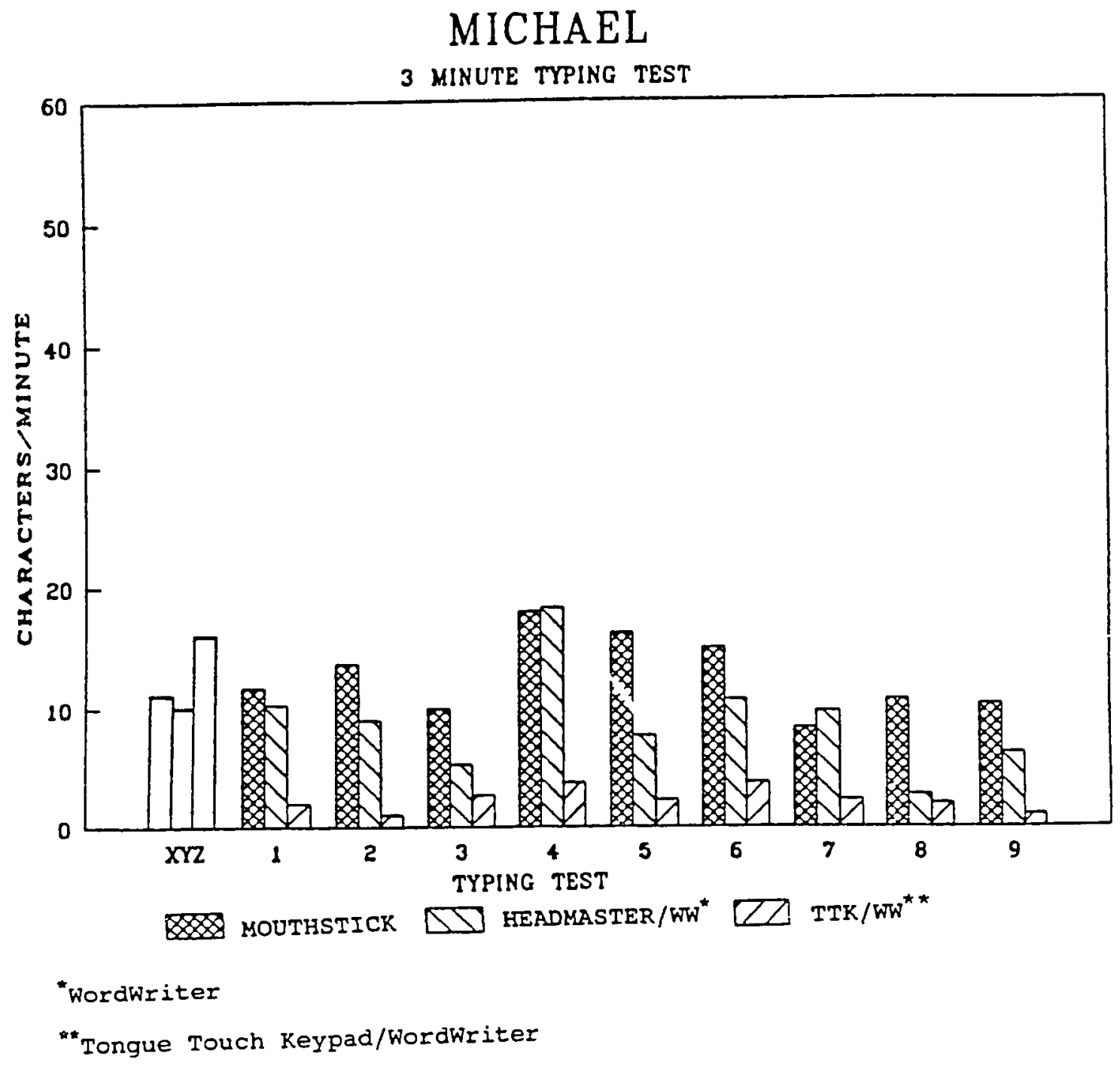


Figure 14

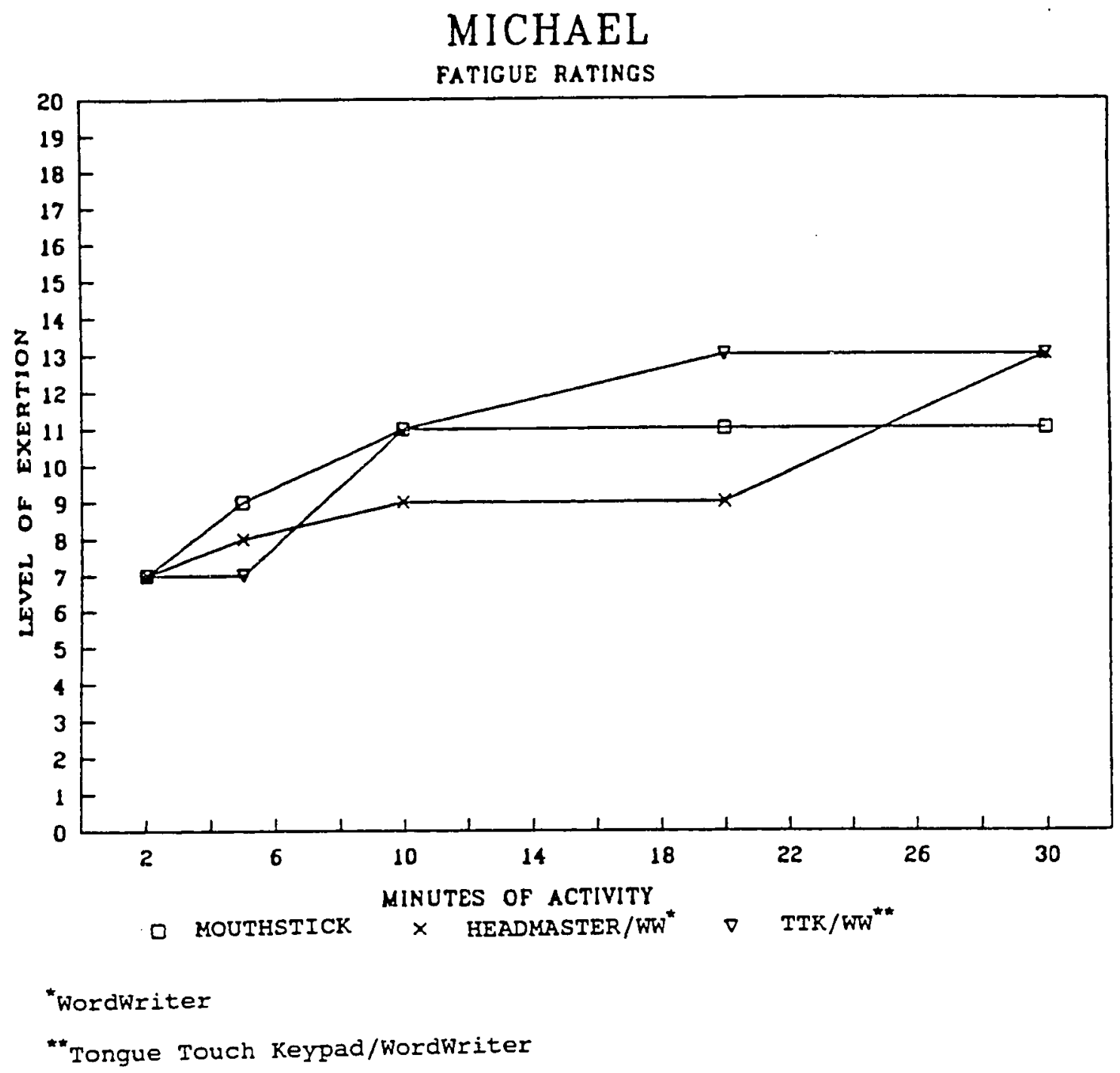


rate of perceived exertion scale over 30 minutes of activity showed Michael's perceived level of exertion increasing at different rates and period of time. He rated the mouthstick as the least tiring; starting out with a "very, very, light" rating and over 30 minutes gradually increasing to a "fairly light" rating. The HeadMaster started with a "very, very, light" rating; exertion increased slowly up to 20 minutes, and then took a quick turn upward ending at a "somewhat hard" rating. The TTK also started with a rating of "very, very, light" and had a sharp incline of exertion between 5 and 10 minutes of activity, and leveled off at "somewhat hard". It appears that Michael would require frequent breaks in order to use the HeadMaster or TTK. Michael performed the fastest and with the least physical exertion with the mouthstick.

\section{Personal Accepiability of the Computer Interface Devices}

Michael rated the TTK highest in personal acceptability with the HeadMaster second and mouthstick third (Figure 15). It was interesting to note that Michael performed the least efficiently using the TTK averaging only $2.3 \mathrm{cpm}$ but rated it the highest in terms of acceptability. According to his responses to the Personal Acceptability Questionnaire, Michael felt the most comfortable and attractive using the TTK. He felt more productive using the HeadMaster and TTK even though these two interface devices were far slower for 
Figure 15

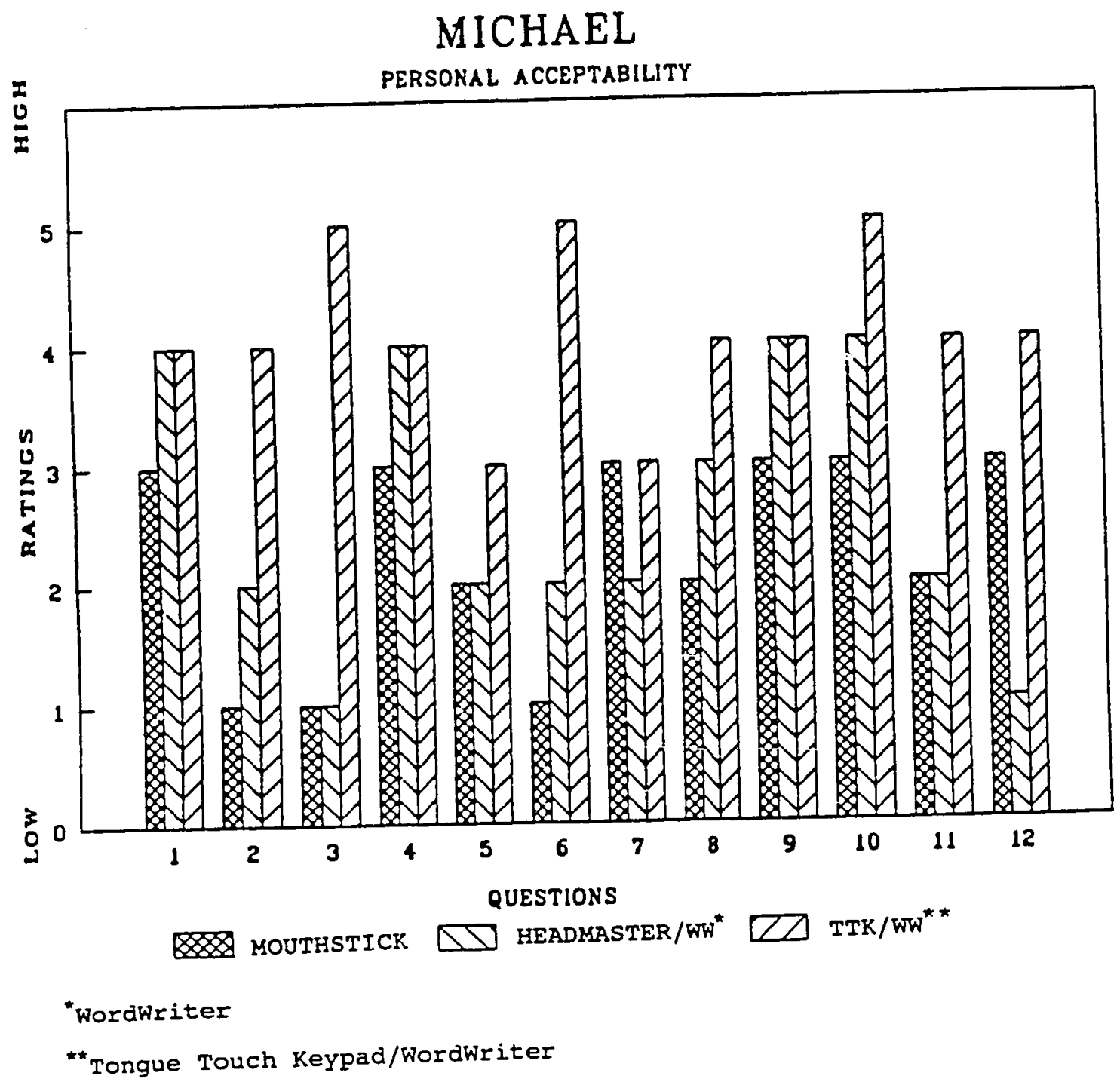


him to use. Michael rated both the mouthstick and HeadMaster as causing neck strain. Michael reported that he did not like using head movements needed for the HeadMaster and mouthstick. In addition, he complained his eyes hurt when using the mouthstick since he needed to look at the typing material, standard keyboard, and computer monitor intermittently. Michael said that the mouthstick interfered with his speech as he had to place the mouthstick on the docking station before he could speak. He claimed the HeadMaster's sip and puff switch that sat at the edge of his mouth also interfered with his speaking ability and that the HeadMaster interfered with the quick or emergency use of his wheelchair. For example, he could quickly place his mouthstick on the docking station but he could not remove the HeadMaster headset without assistance and exit the area quickly. Since the TTK is wireless, Michael could drive off whenever he chose to. Michael would like all three of the devices for his personal use and would alternate them depending upon his physical status and mood.

\section{Exit Interview}

Michael took time away from choir practice with his Young Life Group to participate in the study. He was the most consistent subject in terms of attendance. He did not become ill or miss any classes over the three months of data collection. Michael enjoyed the entire experience of being 
on a sollege campus and taking a computer class. He liked the opportunity to take a break form his high school schedule to take part in the study as part of the Adaptive Computer Application class located at Foothill College, Los Altos. His family was very supportive in his educational and extracurricular activities. They wanted him to learn more about the interface devices that may help him keep his ability to access the computer even with his progressively deteriorating physical condition.

Michael enjoyed all of the technology covered in the study and the social interaction with the other subjects. He suggested that more frequent rest periods between work periods be provided. Overall, Michael liked the TTK best for interfacing with the computer even though he performed extremely slowly with this device. Perhaps operating the computer without hand or head movement served as a novelty. Michael is confident that he could be more efficient on all three devices given additional practice and would like all three with which to experiment further. 


\section{CHAPTER 5}

\section{SUMLARY AND IMPLICATIONS}

\section{Introduction}

Thousands of people in the United states live with physical disabilities that limit movement of all four extremities. Some of these disabilities result from muscular dystrophy and spinal cord injury. A person with either of these disabilities would find it necessary to adapt to the restraints of the environment in order to participate in the areas of work, self-care, and play/ leisure. Persons with disabilities may experience a reduction or termination of role acquisition and participation in activities (Versluys, 1980). With a decrease of achievement in the above areas, a person's role in society could suffer. It is the purpose of occupational therapy to prevent incapacities resulting in illness and to activate residual adaptation forces within a patient to carry out daily activities required by his/her social role (Reilly, 1969; Reed, 1984). Occupational therapists with their knowledge of physical dysfunction, adaptation, and technology are well qualified to train clients to access and use specialized interface devices (Gross \& Burnett, 1989; Vanderheinden, 1987). Unfortunately, with the constantly changing information on computers and technology, it is difficult for occupational therapists to know which 
interface devices are best for each client. It would be helpful to know which interface device works best for persons with only head control and more importantly for what reasons. A model to collect data on input speed, accuracy of input, perceived rate of exertion, and acceptability by the client would provide therapists with a basis for guidance and selection. Due to the relative newness of computer technology for persons with disabilities, reports on the effectiveness and acceptability of computer interface devices are very limited.

\section{Bummary}

The purpose of this study was to determine the input speed, accuracy, and level of perceived exertion by persons with severe physical disabilities on three head operated systems used as computer interface devices: mouthstick, HeadMaster, and Tongue Touch Keypad and to explore the personal acceptability of the devices to the subjects. In order to accomplish this, a descriptive case study design was employed. One subject dropped out during the study due to the pressures of his regular class work, thus leaving four subjects. The four subjects had either muscular dystrophy or spinal cord injury and were between the ages of 17 and 21. They were all males, high school students, and interested in exploring computer interface devices to increase proficiency on the computer. The study took place 
as a segment of the Adaptive computer Application Class at Foothill college, Los Altos, California. Each subject received individual training on all three devices. Baseline tests, typing tests for speed and accuracy, perceived rate of exertion scales, and personal acceptability questionnaires were given for each interface device. The data collection originally scheduled for six weeks was extended to twelve weeks due to illness and transportation problems of the subjects.

All of the subjects had a baseline method of direct access to the computer using a different combination of typing aids such as flexor hinge splints, typing clips, universal cuffs, pens, or using hands alone. Each subject cited his baseline method as ineffective and/or physically tiring on a particular group of muscles. All of the subjects were very enthusiastic about trying the computer interface devices that did not require the use of their hands which were functionally limited. Accuracy was determined by percentage of correctly entered characters per minute. In terms of input accuracy, there was not much variability on any of the devices compared to the baseline for three of the four subjects. One subject, Michael, had lower accuracy using the TTK when compared to the mouthstick and HeadMaster, but the other three subjects performed with all three interfaces with no accuracy scores below 92 
percent.

There was some variability of speed among the different devices. The only interface device that was faster than or equivalent to the subjects' baseline speed was the mouthstick. The subjects would access the computer by hitting the keys of the standard keyboard with the mouthstick. This method is actually closest to the baseline hunt and peck strategy with the hands and/or typing orthosis used by the subjects before the study. Using the mouthstick was the most similar to their baseline methods.

All of the subjects performed the second fastest with the HeadMaster which required head movement and sip and puffs of air to operate. With the HeadMaster, the standard keyboard was replaced by the wordWriter video keyboard on the computer screen. The subjects also learned this indirect computer interface device fairly quickly. The direction of head movement corresponded to the cursor moving on the screen and a puff of air selected a character on the video keyboard.

The subjects had the most difficulty learning to use the TTK and subsequently had the slowest input rate with this device. Each subject was required to learn to elevate his tongue to the roof of his mouth in order to activate separate distinct keys. Unlike the natural act of speaking and eating, the subjects probably never had to use his 
tongue in a conscious motor planning act as needed to use the TTK. The actual selection method of using the WordWriter video keyboard to substitute for the standard keyboard was the same for the HeadMaster and TTK, but the input style of using head movements versus tongue movements to activate a selection was a different experience for the subjects. There was a relation between how long each subject took to learn to use the TTK and how fast each subject performed with it. For example, sam almost used the TTK as fast as the HeadMaster, averaging about $17 \mathrm{cpm}$. Sam reported that he had a "very mobile tongue" and that it was easy for him to isolate the keys. On the other hand, Michael only entered approximately $2.3 \mathrm{cpm}$ with the TTK. After he was given one additional hour of training, it was observed that he had probiems locating the separate keys due to the limited elevation and flatness of his tongue.

Based on the speed of input, it was clear that all of the subjects performed best with the mouthstick, followed by the HeadMaster and the TTK respectively. The perceived rate of exertion scale offered another component of performance to examine. Three of the four subjects rated the TTK as requiring the least exertion over a 30 minute work period. The TTK was the easiest on which to perform because it required no head movement, controlled respiration, or sustained bite as does the HeadMaster and mouthstick. One 
of the subjects (Ernie) rated the TTK as requiring the most exertion because he interpreted the question as referring to mental exertion as well physical exertion.

Three of the four subjects rated the mouthstick as requiring more exertion than the TTK but needing less exertion than the HeadMaster over a 30 minute work period. The slight head flexion and extension and sustained bite necessary to use the mouthstick were apparently more tolerable than the head lateral flexion and rotation and respiration needed to perform on the HeadMaster. Ernie rated the HeadMaster as requiring less exertion than the TTK because he had considered mental as well as physical exertion. The subjects performed best in speed with the mouthstick but the TTK required the least exertion over a 30 minute work period.

From the Personal Acceptability Questionnaire and the exit interview data, it was clear that the four subjects preferred using the TTK over the HeadMaster and mouthstick. Some explanations for this preference were the minimal physical energy required to use it, the aesthetics of a wireless system, and the comfort level provided. The second preference of interface device was divided equally between the HeadMaster and the mouthstick. Two subjects liked the HeadMaster better than the mouthstick because it did not interfere with speech or cause discomfort in the jaw from 
a sustained bite. Two subjects liked the mouthstick better because it performed faster and did not cause strain to the neck as does the HeadMaster.

While all of the subjects rated the TTK highest on personal acceptability with the mouthstick or HeadMaster second, there were some common problems noted by all of the subjects for each device. Using the TTK required the subject to adapt to the intraoral device in order to speak clearly. Tongue tip elevation required by the TTK seemed to be more difficult to isolate and control than the head movements required for use of the HeadMaster and mouthstick. The person who uses the HeadMaster needs strong neck muscles to avoid excessive strain and fatigue. Both the TTK and HeadMaster require an assistant for set up either for inserting the TTK into the user's mouth or for donning the HeadMaster headset on the user's head. The mouthstick and docking station can be an independent set up for a user with physical disabilities. The user can just drive up to the computer, pick up the mouthstick and interface with the computer. The person using a non-custom mouthstick must tolerate biting on the biteplate for a extended period. Even though the mouthstick was the fastest computer interface device, it was consistently rated as the least attractive. 


\section{observations}

The overall goal was to determine how well the three computer interface devices which were studied work for individuals with severe physical disabilities. The following are some observations made by the researcher regarding the subjects' performance on the three computer interface devices. The mouthstick even though rated unattractive by the subjects produced the highest speed of input and is the least expensive computer interface for a person with severe physical disability to purchase. In addition, it can easily be used on any standard keyboard without set up or special software program.

Given that using the mouthstick was most similar to the subjects' baseline method of input, perhaps the subjects could increase their speed with the other two higher technological devices with more practice. The subjects' baseline speed was higher compared to the interface devices possibly because they have had years practicing with the method which was available. All of the subjects rated the TTK very high on personal acceptability. This may be due, in part, to the novelty of operating the computer without hand or head control. In addition, the subjects knew that TTK had the potential to act as an environmental control unit as well. Regardless of how the subjects felt about each device, during the training and testing phase, each 
concentrated on optimizing speed and accuracy.

From this study, it was further observed that each individual subject had different expectations and priorities when it came to what technology could provide. For example, one subject expressed interest in using the mouse function primarily for art work, another was very interested in playing video games with his brothers on the computer, while the third subject reported a desire to increase his input for data entry for a potential job, and the last wished to use the computer for reaching educational goals.

\section{Implications}

There are several implications from this study for occupational therapy. Persons with physical disabilities may have excessive free time, a higher rate of unemployment, and decreased life satisfaction compared to their nondisabled counterparts (Versluys, 1980; Yerxa \& Locker, 1990). In this age of technology, it will not be long before all therapists will be involved in some type of rehabilitation involving computer use. Computers can be the key to the rehabilitation, employment, and fulfillment of social roles for persons with severe physical disabilities. By training students who have severe physical disabilities on the computer, an opportunity can be created for them to reach educational and vocational goals beyond 
the high school level and therefore facilitate the adult roles of college student and employee. Before training clients on computers, there needs to be more exploration of the different types of computer interface devices available, how well they work for the designated population, and why they work.

From this study, it is recommended that when working to match clients with technology, it is important to explore the values of the client in terms of personal acceptability. The importance of aesthetics, physical comfort, and psychological comfort should be considered. As shown in this study, the best performing interface device may not be the most acceptable. Therapists who often prescribe wheelchairs, adaptive home equipment and now computer interface devices, must be careful not to give a workable piece of equipment to a client which he/she will rarely or never use because it is not personally acceptable. Another recommendation is to investigate the cost of the interface device and the feasibility of funding for the client before introducing him or her to it. The cost of interface devices were not addressed completely in this study but did emerge as a concern during the exit interviews. Even though the subjects were introduced to three interface systems, and were interested in continuing to use them, they did not necessarily have the financial 
resources to purchase the HeadMaster or TTK. Introducing technology to people with physical disabilities is just the first step. Setting up training centers such as the Computer Evaluation Learning Lab at the Palo Alto Veterans Administration Medical Center would be a next step. Initiating private and public funding programs to make technology a reality for persons with disabilities in the community is another consideration.

In this study, occupational behavior was represented by learning and attainment of computer access through a specialized computer interface device. The intervention strategy of providing computer access through training and equipment is concerned with providing the opportunity for individuals with disabilities to have control over their environment, introducing them to a more effective utilization of time, and fulfilling social roles.

Every individual had his personal goals for computer access and for fulfilling different roles in social, work, and leisure settings. It would be important for occupational therapists to know the patient's goals and the settings in which the client will use the computer most often before recommending a system that may be too extensive and expensive for the client's needs.

occupational therapy and rehabilitation technology make an important contribution to the rehabilitation process. An 
occupational therapist can provide work endurance, psychosocial, cognitive and occupational behavior information to the rehabilitation team by using computer access training. Speed and accuracy of input data are very important, but perceived rate of exertion along with personal acceptability are also vital in examining the needs of the client. In addition, an occupational therapist can provide information to rehabilitation engineers which can be used to improve already existing interface devices. For example, the bite plate of the mouthstick could be improved with nuore padded material or customized shaping. The HeadMaster headset can easily be altered to be adjustable to different head sizes. The prototype Tongue Touch Keypad from Zofcom, Incorporated has already received input from this researcher regarding reducing the size of the TTK for comfort and increasing the size of the keys for easier tactile discrimination. continuing research by therapists to further investigate the performance of computer interface devices along with other technology in combination with personal acceptability will better assist the population of individuals with severe physical disabilities to reach their goals and fulfill life roles. 


\section{REFERENCES}

Adler, C. \& Pedretti, L. W. (1990). Spinal cord injury. In L. W. Pedretti and B. Zolton (Eds.). Occupational therapy: Practice skills for physical dysfunction.

(pp. 403-418). St. Louis: C. V. Mosby Company. American Occupational Therapy Association. (1990). 1990 Member data survey: Summary report. Maryland, Rockville: Author.

Angelo, J. (1989). A comparison of three optical head pointing systems. Paper presented at the 1989 Closing the Gap Conference, Minneapolis, Minnesota.

Angelo, J. \& Smith, R. O. (1989, April). The critical role of occupational therapy in augmentative communication services. Paper presented at the 1989 American Occupational Therapy Association Conference, Phoenix, Arizona.

Batavia, A. \& Hammer, G. (1990). Consumer criteria for evaluating assistive devices: Implications for technology transfer. Paper presented in the Proceedings of California State University at Northridge Fifth Conference on Technology and Persons with Disabilities, Los Angeles, CA.

Borg, G. (1982). Psychophysical bases of perceived exertion. Medicine and Science in Sport and Exercise, $14,377-381$. 
Bowe, F. \& Iittle, N. (1984). Computer accessibility: A study. Rehabilitation Literature, 45, 289-290.

Bryant, H. (1989, November). Computer Assisted Rehab. OT Week. pp. 6-7.

Burkhead, E. J., Sampson, J. P., \& McMahon, B. T. (1986).

The liberation of disabled persons in a technological

society: Access to computer technology.

Rehabilitation Literature, 47, 162-168.

Corcoran, P. (1985). Neuromuscular diseases. In W. C.

Stolov \& M. R. Clowers (Eds.). Handbook of severe

disabilities, (pp.137-154). U.S. Department of

Education: Rehabilitation Services Administration.

Decker, S. \& Schulz, R. (1985). Correlates of life

satisfaction and depression in middle-aged and elderly

spinal cord-injured persons. American Journal of

Occupational Therapy, 39, 740-745.

Dickey, R. \& Shealey, S. (1987). Using technology to

control the environment. American Journal of

occupational Therapy, 41, 717-721.

Easton, J. \& Halpern, D. (1985). Cerebral palsy. In W. C.

Stoiov \& M. R. Clowers (Eds.). Handbook of severe

disabilities, (pp. 137-154). U.S. Department of

Education: Rehabilitation Services Administration.

Gross, K. \& Burnett, S. E. (1989, April). Adapted computer

technology. Paper presented at the 1989 American 
Occupational Therapy Conference, Phoenix, Arizona. Howell, L. (1978). Spinal cord injury in R. M. Goldenson, J. R. Dunham, \& C. S. Dunham (Eds.), Disability and Rehabilitation Handbook. (pp. 78-83). New York: McGraw-Hill.

Kanellos, M. C. (1985). Enhancing vocational outcomes of spinal cord-injured persons. The occupational therapist's role. American Journal of Occupational Therapy, 39, 726-733.

Links, C. and Frydenberg, H. (1989). Microcomputer skills training program for the physically disabled in long term rehabilitation. Physical and occupational Therapy in Geriatrics, $\underline{6}, 133-140$. Matsutsuyu, J. (1971). Occupational behavior - A perspective on work and play. American Journal of Occupational Therapy, 25, 292-293.

O' Leary, S., Saxena, K., Linder, S. H., \& Perkash, I. (1990, March). Computer access for patients with spinal cord injury during rehabilitation. Paper presented in the Proceedings of California state University at Northridge Fifth Conference on Technology and Persons with Disabilities, Los Angeles, CA.

Owen, B. (1976). Typing for beginners. New York, NY: Putnam. 
Protor, S. (1989). Subject profile. Written for use by Zofcom, Incorporated, Palo Alto, CA. Reed, K. I. (1984). Models of practice in occupational therapy. Baltimore, MD: Williams \& Wilkins.

Reilly, M. (1969). The educational process. American Journal of Occupational Therapy, 23, 299-307. Schneider, F. J. (1985). Traumatic spinal cord injury. In D. A. Umphred (Ed.). Neurological rehabilitation (pp. 314-373). St. Louis: C. V. Mosby Company. Smith, R., Christiansen, R., Borden, B., Linberg, D., Gunderson, J., \& Vanderheiden, G. (1989). Effectiveness of a writing system using a computerized long-range optical pointer and 10-branch abbreviation expansion. Journal of Rehabilitation Research and Development, 29 , $51-62$.

Spencer, E. A. (1983). Functional restoration - Specific diagnoses. In H. L. Hopkins \& H. D. Smith (Eds.). Willard and Spackman's: Occupational therapy (pp. 381445) . Philadelphia: J. B. Lippincott Company. Spicer, M. M. \& McMillan, S. L. (1987). Computer's and occupational therapy. American Journal of Occupational Therapy, 41, 726-732.

Stride, B. D. (1985). Computer vocations for severely physically disabled persons: Survey results. Archives of Physical Medicine and Rehabilitation, 66, 505-507. 
Sunahara, S. (1990). Effectiveness of computer access technology for students's word processing. Technology Review 190: Perspectives of occupational therapy practice. Rockville, MD: American Occupational Therapy Association

Trefler, E. (1987). Technology applications in occupational therapy. American Journal of Occupational Therapy, 41 , $697-699$.

Vanderheiden, G. (1983). The practical use of microcomputers in rehabilitation. Rehabilitation Literature, $44,66-70$.

Vanderheiden, G. (1987). Service delivery mechanisms in rehabilitation technology. American Journal of Occupational Therapy, 41, 703-710.

Versluys, H. P. (1980). The remediation of role disorders through focused group work. American Journal of Occupational Therapy: 34, 609-614.

Wall, N. (1985). Work-related programs, the microcomputer, and occupatioisal therapy in $\mathrm{K}$. Jacobs (Ed.), occupational therapy: Work-related programs and assessments. (pp. 275279). Boston: Little, Brown and Company.

White, G. W., Wussow, A. E. \& Merritt, J. L. (1984) . Videogame adaptation for patients with high-level cervical injury. Archives of Physical Medicine and Rehabilitation, 66, 505- 507 . 
Woodside, H. (1976). Dimensions of the occupational

behaviour model. Canadian Journal of occupational

Therapy, 43,11 .

Yerxa, E. J. \& Locker, S. B. (1990). Quality of time use

by adults with spinal cord injuries. American Journal of

Occupational Therapy, 44, 318-326. 
APPENDIX A

SUBJECT PROFILE FOR EVALUATION 


\section{SUBJECT PROFILE FOR EVALUATION}

Date form completed:

Form completed by:

Location:

\section{Personal Background}

1. Name:

Sex:

2. Birth date: Age:

Marital status:

3. Home address:

City: State:

zip:

Phone: 1

5. Occupational Roles:

Years worked:

6. Highest academic level:

7. Present living situation:

8. Future living situation:

9. Desired living situation:

10. Vocational Goals:

11. Do you have legal custody to sign?

Who does? 


\section{Medical Background}

1. Medical diagnosis:

2. Cause of disability:

3. Pre-existing medical conditions:

4. Date of onset:

Length of disability:

5. Hospital Name and Address:

Street:

city:

state:

zip

Phone: $(1)$

6. Dates of rehabilitation: From

to

7. Attending physician:

8. Occupational Therapist:

9. Physical Therapist:

10. How are you paying for medical care?

11. How are you paying for durable medical equipment?

12. How will medical care be paid over the next 5 years? 


\section{Physical Background}

1. Vision: (circle) 20/20 Nearsighted Farsighted Corrected

2. Hearing: (circle) normal impaired corrected with aid

3. Muscle strength

(Check appropriate box)

Face:

Tongue movement:

oral control:

Neck:

Flexion:

Extension:

Rotation:

Shoulders:

Flexion:

Abduction:

Internal/External

Rotation:

Elbows:

Flexion:

Extension:

Forearms:

Supination:

Pronation:

Wrist:

Flexion:

Extension:

Fingers:

Flexion:

Extension:

Fine manipulation:

4. Sensation:

(Check appropriate box)

Tongue and mouth:

Face:

Neck:

Shoulders:

Arms :

Hands:

Trunk:

Legs:
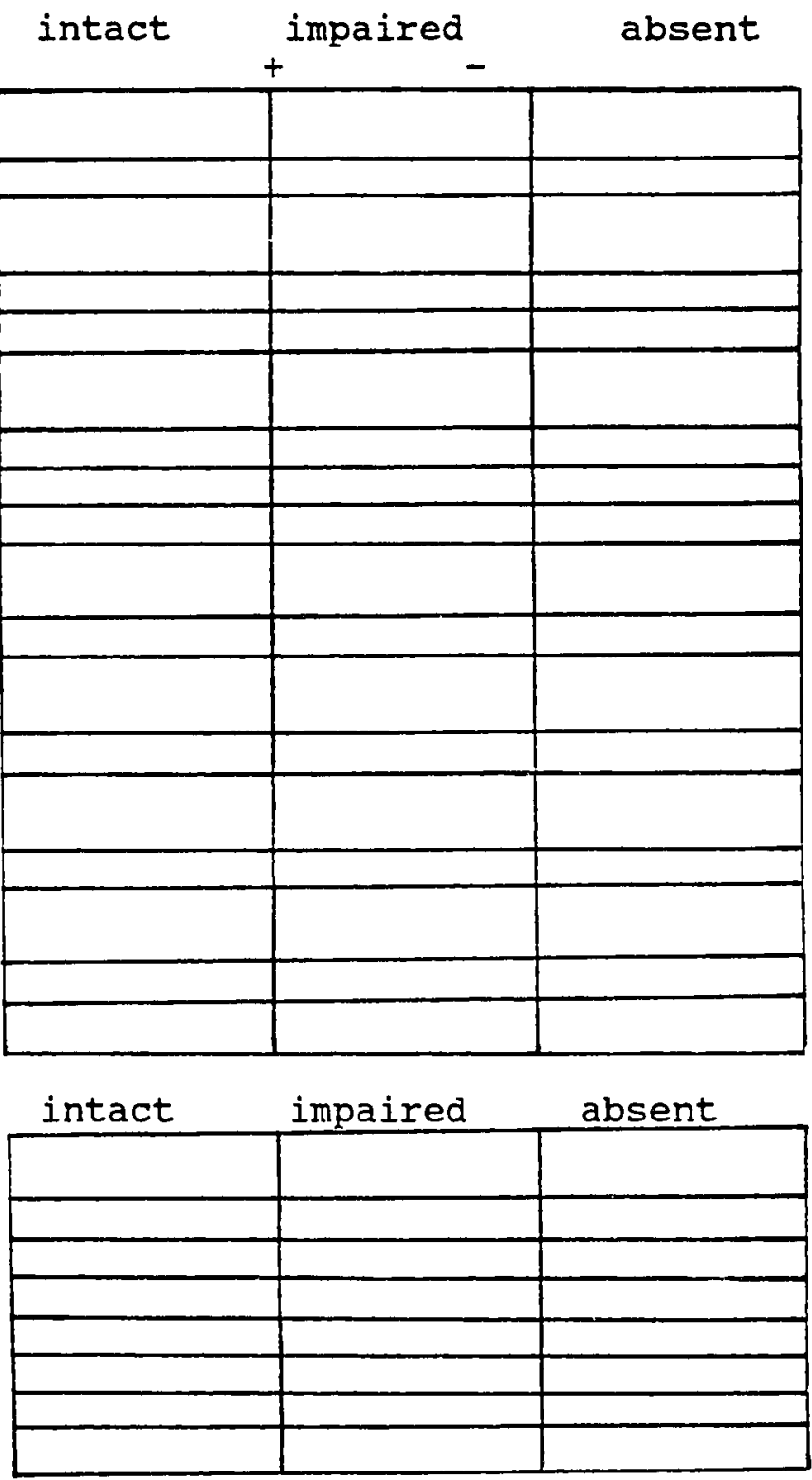

5. Fatigue sets in after hours of being up in a w/c. 


\section{Functional Background}

1. Do you know how to type? WPM: Before After

2. Years of computer use: Computer brand/model:

Applications:

Functions (circle)

yes no -Business:

yes no -word Processing

yes no -Programming

yes no -Graphics

yes no -Recreation

3. Equipment owned or currently in use:

Controlled by/Brand Able to use

Mobility aids: (circle) independently?

yes no -Electric wheelchair

(circle)

yes no -Manual wheelchair

yes set no

yes no -Van

yes set no

yes set no

Communication aids:

(circle)

yes no -call switch

(circle)

yes set no

yes no -Telephone

yes set no

yes no -Computer system

yes set no

yes no -Writing orthosis

yes set no

yes no -Typewriter

yes set no 
4. Controllers that have been tried or are currently using: Are you able to use this functionally?

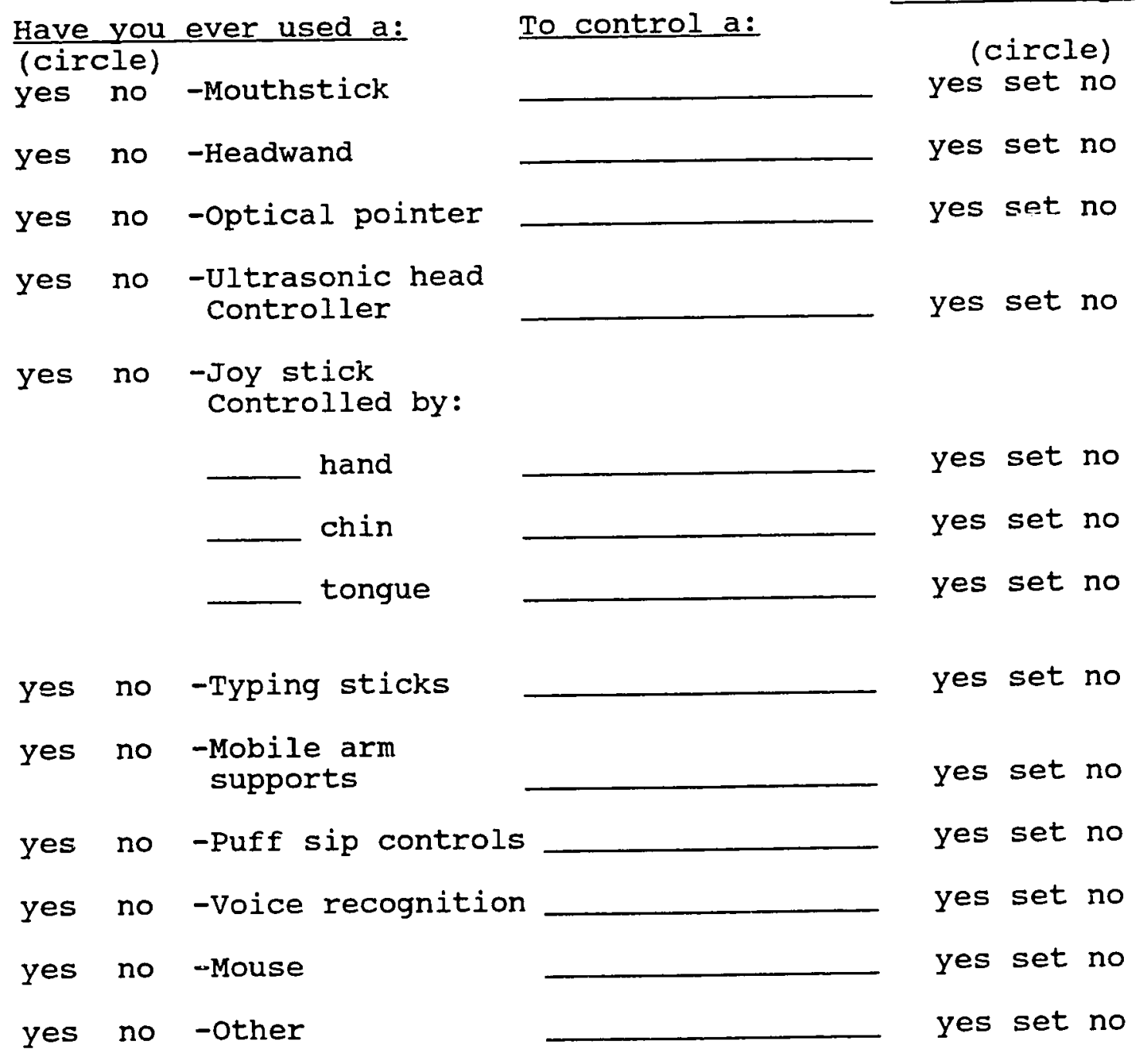

5. Hours per day spent in: Wheelchair: Bed : Other (s):

6. Hours per day of attendant care: 
7. How much assistance do you require from a person for: (Circle level of assistance and list functions)

-Wheelchair mobility maximum moderate minimal set up needed (list functions being assisted)

-Feeding

-Drinking

-Brushing teeth

-Writing

-Using the Computer

-Controlling the Television

-Controlling the Radio

-other maximum moderate minimal set up needed maximum moderate minimal set up needed maximum moderate minimal set up needed maximum moderate minimal set up needed maximum moderate minimal set up needed maximum moderate minimal set up needed maximum moderate minimal set up needed maximum moderate minimal set up needed 
100

APPENDIX B

CONSENT FORM 
School of Applied Arts and Sciences. - Department of Occupational Therapy

One Washington Square - San Jose. California 95192-0059 - Main Office: 408/924-3070 • Fieldwork Offıce: 408/924-307ó

\section{AGREEMENT TO PARTICIPATE IN RESEARCH SAN JOSE BTATE UNIVERSITY}

\section{RESPONSIBLE INVESTIGATOR: Cynthia Lau}

TITLE OF PROTOCOL: The performance of persons with severe physical disabilities on computer interface devices.

I have been asked to participate in a research study that is investigating computer interface devices. The results of this study should further our understanding of how well these devices work for the disabled population.

I understand that

1) I will be asked to take the Adaptive Computer Applications class in the winter quarter at Foothill college. The class is two hours a week for seven weeks.

2) the possible risks of this study are fatigue, eye strain, and head and neck pain due to the physical demands of the class.

3) the possible benefits of this study to me are 1.5 college units and the experience of evaluating adaptive computer equipment.

4) the results from this study may be published, but any information from this study that can be identified with me will remain confidential and will be disclosed only with my permission.

5) any questions about my participation in this study will be answered by Cynthia Lau at (415)334-5240. Complaints about the procedures may be presented to Lela Llorens, Ph.D., OTR, Chair, Department of Occupational Therapy at San Jose State University at (408)924-3070. For questions or complaints about research subject's rights contact Serena stanford, Ph.D., Associate Academic Vice President for Graduate Studies at (408)924-2480.

6) my consent is given voluntarily without being coerced; I may refuse to participate in this study or in any part of this study, and I may withdraw at any time, without prejudice to my relations with SJSU and Foothill Colleçe. 
7) I have received a copy of this consent form for my ilie.

I HAVE MADE A DECISION WHETHER OR NOT TO PARTICIPATE. MY SIGNATURE INDICATES THAT I HAVE READ THE INFORMATION PROVIDED ABOVE AND THAT I DECIDED TO PARTICIPATE. 
103

APPENDIX C

DATA COLLECTION SHEET 
DATA COLLECTION SHEET

Subject

Date Consent Form Signed

Pretraining method of using computer

Baseline scores of pretraining method

Training time required to learn baseline sentence for: Tongue Touch Keypad.

HeadMaster

Mouthstick

Tongue Touch Reypad

Perceived Exertion Ratings

2 minutes

5 minutes

10 minutes

20 minutes

30 minutes

* CPM (Characters per minute)

Three Minute Typing Tests

Test (1-3) Letters

CPM/Accuracy

Test $(4-6)$ Numbers

CPM/Accuracy

Test (7-9) All Keys

CPM/Accuracy

HeadMaster

Perceived Exertion Ratings

2 minutes

5 minutes

10 minutes

20 minutes

30 minutes

Three Minute Typing Tests

Test (1-3) Letters

CPM/Accuracy

Test (4-6) Numbers

CPM / Accuracy

Test (7-9) All Keys

CPM/Accuracy 


\section{Mouthstick}

Perceived Exertion Ratings

2 minutes

5 minutes

10 minutes

20 minutes

30 minutes

Three Minute Typing Tests

Test (1-3) Letters

CPM/Accuracy

Test $(4-6)$ Numbers

CPM/Accuracy

Test (7-9) All Keys

CPM/Accuracy

CPM (Characters Per Minute): Take this total number of entered characters and divide by number of minutes typed.

Accuracy: Take number of characters correctly typed and divide by total number of characters typed. 
106

APPENDIX D

PERCEIVED EXERTION SCALE 


\section{Rate of Perceived Exertion (RPE) scale}

How much exertion are you using for the activity you completing?

Please indicate the number that best represents the level of exertion.

6

7 Very, very light

8

9 Very light

10

11 Fairly Light

12

13 Somewhat hard

14

15 Hard

16

17 Very hard

18

19 Very, very hard

20

(Borg, 1982) 
108

APPENDIX $\mathrm{J}$

TYPING TEIST 


\section{TYPING TESTS}

Baseline Sentence:

Don't expect to zoom through the next sentence: "Her birthday is $08 / 15 / 53 . "$

Baseline Tests XYZ:

Date, Mrs. Mary Mansfield, Center for Urban Education, 300 Madison Avenue, New York, NY 10017. Dear Mrs. Mansfield: Your analysis of our film script outline was so constructive I have passed it along to everyone on our staff.

Date, Mrs. Andrews, 5 Outlook Lane, Mountaintop, Mo 54962. Dear Mrs. Andrews, on Friday, April 17, Mrs.Holmes will ring your doorbell. She is your new Avon Lady and will be serving you for the coming year.

Date, Mr. Matthew stockbridge, 100 Elm Street, Troy, NY 12180. Dear Mr. Stockbridge; Your request for a \$100 grant to develop an ecology program for the elementary grade level has been turned over to me for consideration.

Three Minute Typing Tests

Test 1:

A sunny day in spring is a glorious, glorious time of year. People bring out their bicycles to ride and bask in the sun. Girls and boys go running down the street after runaway dogs.

Test 2:

Men and women gather on the sunny side to enjoy the warm sun. The yellow and red tulips and pink azaleas are in full bloom. The sky is very blue and there is no wind to blow the clouds.

Test 3:

Learning to type takes lots of concentration and hard work. Every five strokes count as one word in figuring your speed. You have a sense of freedom when you can type your own papers.

Test 4:

$\begin{array}{lllllllllllllll}444 & 333 & 222 & 111 & 666 & 555 & 777 & 888 & 999 & 000 & 898 & 789 & 909 & 707 & 808\end{array}$ $\begin{array}{llllll}767 & 676 & 868 & 969 & 123 & 456\end{array}$ 
Test 5:

$\begin{array}{lllllllllllllll}384 & 279 & 482 & 394 & 687 & 777 & 010 & 111 & 000 & 222 & 999 & 759 & 274 & 249 & 147\end{array}$

$\begin{array}{llllll}981 & 721 & 964 & 161 & 802 & 300\end{array}$

Test 6:

$\begin{array}{llllllllllllll}400 & 710 & 147 & 183 & 502 & 472 & 710 & 329 & 798 & 100 & 297 & 395 & 1972 & 1973\end{array}$

$1974 \quad 1975 \quad 1976 \quad 1977 \quad 1978 \quad 1979$

Test 7:

Don't be concerned if you aren't typing as quickly as you can; Everyone has a quandary with number and symbol keys.

Test 8:

Does $73 \%$ of $\$ 546.00=\$ 398.58$ ? Item \# 32 (jonquils) sold 2 units a $\$ 73$.

Test 9:

Nancy Midkiff quivered around Thorton around 10:19:32 PM. The strategist (siifting beside this office) quails! 
111

AFPENDIX $F$

PERSONAL ACCEPTABILITY QUESTIONNAIRE 
Personal Acceptability Questionnairo

Please indicate the number that most accurately describes your feelings about the interface device.

1. I feel happy about using this interface device. Strongly

Disagree

Neutral

Agree
1
2
3
4
5

2. I feel comfortable when using this interface device.
1
2
3
4
5

3. I feel attractive when using this interface device.
1
2
3
4

4. I feel more productive using this interface device.
1
2
3
4
5

5. It was a strain on my neck to use this interface device.
1
2
3
4
5

6. It was a strain on my eyes to use this interface device.

$\begin{array}{lllll}1 & 2 & 3 & 4 & 5\end{array}$

7. It was a strain on my mind to use this interface device.
1 2 3
4
5

8. I feel this interface device can improve my living situation.
1
2
3
4
5

9. I feel this input system can enhance my independence. 
10. I would like to have this interface device for my own use.
1
2
3
4
5

11. Using this interface device interferes with my ability to speak or communicate.
1
2
3
4
5

12. Using this interface device interferes with my other assistive devices.

1

2

3

4 
114

APPENDIX G

EXIT INTERVIEN 


\section{EXIT INTERVIEW}

This interview will be audiotaped. The following questions are to address your attitude regarding the class, the instruction provided, and the technology you used. Please feel free to express your opinion.

1. What did you like about the class?

2. What did you not like about the class?

3. How was the instruction provided?

4. What did you enjoy learnirg the most?

5. What was the most difficult thing to learn?

6. How can we change the class to make it better?

7. Would you like to use any of the technology covered in class in the future?

8. Did the class meet your expectations? How?

9. Do you have any additional comments refarding the class? 
116

APPENDIX H EQUIPMENT 


\section{Hardware}

Macintosh Computer

Macintosh Computer

Adlib Mouthstick

Prentke Romich Company

Headmaster

Zofcom Incorporated

Tongue Touch Keypad

Adlib Tabletop

Docking Station

software

WordWriter

Video Keyboard

Typing Tutor
Mode1

Classic

Classic

$A D-8028$

1.0

F Series

$A D-905$

Version

1.0

4
Serial Number

E1095MDM04 35LL-N

E1098NDM0435LL-A

not available

not available

Version 90.12

not available

\section{Company}

McIntyre Computer systems

Kriya system simmon and Schuster Software 